\title{
Valorization of Biomass-Derived Platform Molecules via Photoredox Sustainable Catalysis
}

\author{
Qiong $\mathrm{Lin}^{1,2} \cdot$ Yue-Hua $\mathrm{Li}^{1,2} \cdot$ Zi-Rong Tang ${ }^{2} \cdot$ Yi-Jun $\mathrm{Xu}^{1,2}$
}

Received: 10 July 2020 / Revised: 19 July 2020 / Accepted: 29 July 2020 / Published online: 28 August 2020

(c) The Author(s) 2020

\begin{abstract}
The conversion of biomass into valuable chemicals has promise for application in biorefineries. Light-driven photoredox catalysis, with the typical features of green route and operation under mild conditions, is considered a promising strategy for renewable biomass or biomass-derived intermediates conversion into high-value-added chemical feedstocks. In this review, we strongly emphasize the recent advances in photocatalytic valorization of lignin model compounds and biomassderived alcohols. We briefly summarize the advances in photocatalytic cleavage of the $\beta-\mathrm{O}-4$ bond or $\mathrm{C}-\mathrm{C}$ bond into usable chemicals in the lignin model. On the other hand, we clarify not only the hybrid system for cooperative biomass-relevant alcohols oxidation and hydrogen $\left(\mathrm{H}_{2}\right)$ evolution but also the tunable accessibility to variation of the target products from the same alcohol reactant by catalyst design and optimization of reaction conditions. It is hoped that this review will inspire the rational design of photoredox catalysis-based systems toward efficient biomass-derived platform molecules valorization to obtain target-oriented valuable products.
\end{abstract}

Keywords Biomass $\cdot$ Photoredox catalysis $\cdot$ Value-added chemicals $\cdot$ Selective oxidation

\section{Introduction}

Exploring the alternative and sustainable feedstocks has recently attracted substantial attention because of the shortage of fossil resources [1]. Biomass, which is available in large amounts and includes all animals, plants, and microorganisms, is an important part of renewable energy [2]. Thus, the efficient development and use of biomass will play a very vital role in resolving energy and ecological issues. Lignocellulose is a typical representative of biomass consisting of lignin, hemicellulose, and cellulose. Among these substances, lignin, which accounts for $30 \%$ of the total mass [3], is the only relevant renewable feedstock for aromatic compounds [2]. Although the traditional strategies for the transformation and fragmentation of lignin have made progress, the high energy consumption and harsh reaction conditions

Yi-Jun Xu

yjxu@fzu.edu.cn

1 State Key Laboratory of Photocatalysis on Energy and Environment, College of Chemistry, Fuzhou University, Fuzhou 350116, China

2 College of Chemistry, New Campus, Fuzhou University, Fuzhou 350116, China are always hazardous to the environment. In contrast, the bio-enzymatic degradation of lignin can occur under mild conditions, but the higher cost of enzyme increases the overall cost of the process [4]. Within this context, photocatalytic valorization of biomass has received substantial attention because of its low energy consumption and secondary-pollution-free operation [5-9].

Noticeably, the photoredox-catalyzed conversion of biomass-derived alcohols (such as 5-hydroxymethylfurfural, furfural alcohol and benzyl alcohol) has also attracted considerable attention in recent years (Fig. 1), because the produced carbonyl or $\mathrm{C}-\mathrm{C}$ coupling compounds are important intermediates for the synthesis of high value-added fine chemicals $[10,11]$. In particular, the visible-light-driven cooperative biomass-relevant alcohols oxidation and hydrogen $\left(\mathrm{H}_{2}\right)$ evolution can occur in one photoredox catalysis system, and in this scenario the photogenerated electrons and holes are simultaneously used to acquire upgraded chemicals as well as clean fuels [12-15]. Additionally, photocatalytic selective conversion of alcohols can be tuned to achieve different product distributions (e.g., aldehydes, ketones or $\mathrm{C}-\mathrm{C}$ coupling compounds) $[16,17]$, which further promotes the flexibility of target-oriented product synthesis from biomassderived alcohols. 


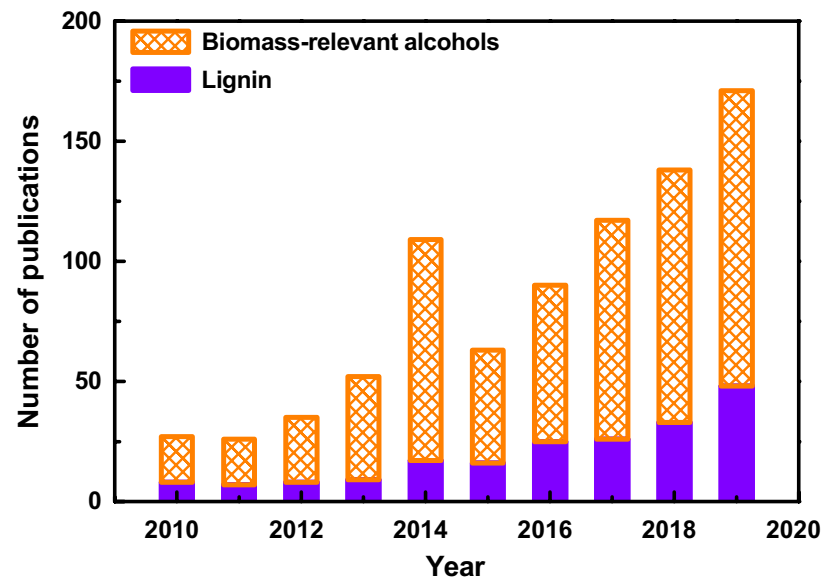

Fig. 1 Number of yearly publications with the keywords "photocatal* \& lignin", "photocatal* \& 5-hydroxymethylfurfural", "photocatal* \& furfural alcohol" and "photocatal* \& benzyl alcohol" since 2010 (The biomass-relevant alcohols include 5-hydroxymethylfurfural, furfural alcohol and benzyl alcohol; data are obtained from the ISI Web of Science)

In this review, we intend to concisely overview recent developments in the solar energy-driven photoredoxcatalyzed transformation of biomass-derived compounds into useful chemical feedstocks, which includes selective fragmentation of lignin, biomass-derived alcohols oxidation, and dual-function selective alcohols conversion coupling with $\mathrm{H}_{2}$ production in a cooperative manner. We also clarify the adjustable flexibility of switching the different target-oriented product distributions from the same alcohol substrate. Furthermore, the brief descriptions for the possible mechanism toward selective lignin model alcohols transformation or biomass-derived alcohols conversion are elaborated. Toward the end, the potential opportunities for future research toward biomass-derived platform molecules valorization are discussed, which we hope will contribute to the development of rational design of efficient photocatalysts for target solar-to-chemical transformations of biomassderived platform molecules to target value-added feedstocks.

\section{Photocatalytic Conversion of Lignin Models}

Lignin, as a complex alcohol-containing molecule originating from lignocellulosic biomass, is considered the only relevant renewable feedstock for aromatic compounds [2]. The interlinkages of lignin primarily contain $\mathrm{C}-\mathrm{O}$ bonds and $\mathrm{C}-\mathrm{C}$ bonds, wherein the $\beta$-O- 4 bond is greatest in content (Fig. 2a) $[18,19]$, and the $\beta$-O-4 bond can be broken down into chemically useful fragments [20]. Likewise, rupturing the $\mathrm{C}-\mathrm{C}$ bond can yield valuable compounds, but cleaving the $\mathrm{C}-\mathrm{C}$ bond of lignin is more difficult because of its relatively high bond dissociation energy (BDE) [21, 22]. Owing to the recalcitrance and complexity of raw lignin, many studies have used representative lignin model compounds to replace lignin macromolecules to explore the potential of lignin valorization into high-value chemicals. Figure $2 b$ depicts a typical lignin model that can be converted into several low-molecular-mass aromatic compounds, which can be further used to synthesize other value-added chemicals. Although lignin model compounds minimize the challenges of lignin fragmentation, certain mild conditions still cannot meet the requirements of their efficient transformation. In this regard, semiconductor-based photoredox catalysis has emerged as an accessible approach to organic synthesis [23, 24], e.g., selective alcohol oxidation [25, 26] and nitroaromatic reduction reactions [27, 28]. To this end, solar energydriven fragmentation of lignin models into useful aromatics has received considerable attention.
Fig. 2 a Illustration of the lignin structure and its typical linkages. Reprinted with permission from Ref. [5]. Copyright 2015 American Chemical Society. b Schematic illustration of a typical lignin model conversion into possible aromatic compounds

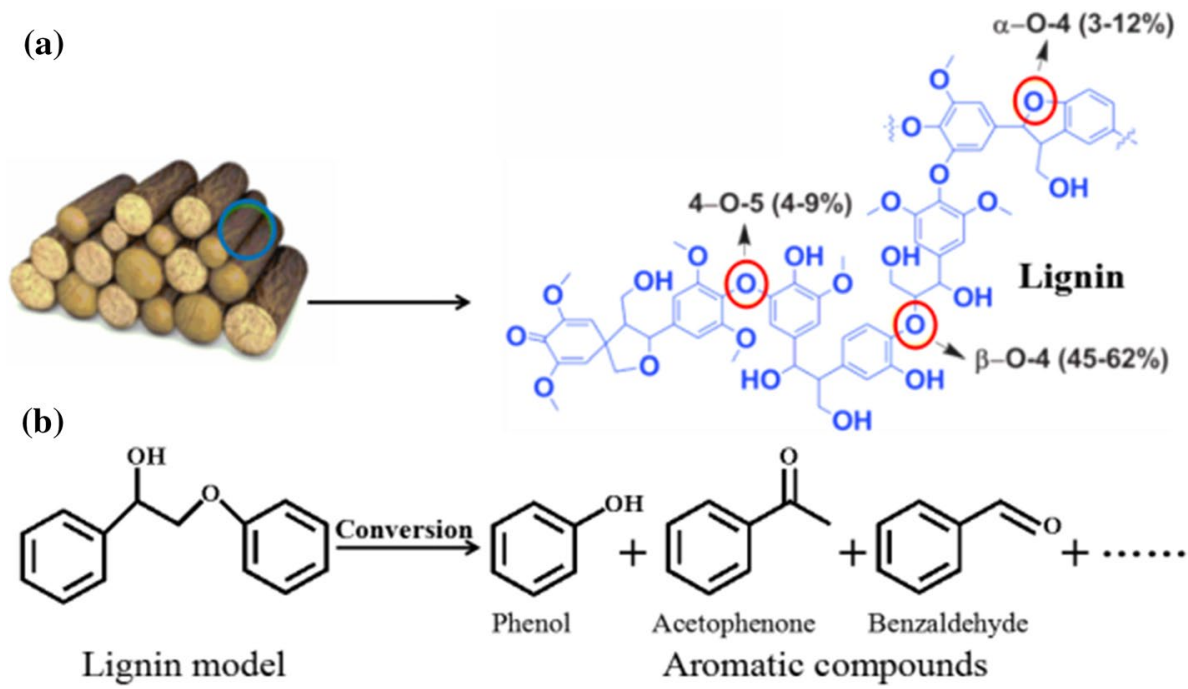




\section{$\beta-0-4$ Bond Cleavage}

The pivotal problem of lignin fragmentation is the scission of $\beta$-O-4 bonds. Catalytic cleavage of the $\beta$-O- 4 linkage in lignin evidently undergoes a two-step continuous process (Fig. 3) [29]. In the first step, an oxidation catalyst is used to oxidize $\mathrm{C}_{\alpha} \mathrm{H}-\mathrm{OH}$ groups into $\mathrm{C}_{\alpha}=\mathrm{O}$. Afterward, the oxidation catalyst is separated out, and then the $\mathrm{C}_{\beta}-\mathrm{O}$ bond is ruptured into aromatic monomers by addition of a hydrogenation catalyst. However, this method uses two catalysts that work independently under oxidizing and reducing conditions. To predigest the reaction steps and boost yields, a photocatalytic oxidation-hydrogenolysis tandem system for rupturing the $\beta-\mathrm{O}-4$ bonds of the lignin model via a dual light wavelength switching strategy has been designed by Luo et al. [30], in which the $\alpha-\mathrm{C}-\mathrm{OH}$ moiety of the lignin model is oxidized to $\alpha-\mathrm{C}=\mathrm{O}$ by $\mathrm{Pd} / \mathrm{ZnIn}_{2} \mathrm{~S}_{4}$ under $455 \mathrm{~nm}$ wavelength light, and then the titanium dioxide-sodium acetate $\left(\mathrm{TiO}_{2}-\mathrm{NaOAc}\right)$ system is applied in rupturing the $\mathrm{C}-\mathrm{O}$ bond neighboring the $\alpha-\mathrm{C}=\mathrm{O}$ bond by switching to $365 \mathrm{~nm}$ wavelength light (Fig. 4a). As a result, the $\mathrm{C}-\mathrm{O}$ bonds are cleaved to yield phenols and acetophenone with high selectivity under aerobic conditions. Additionally, in the $\mathrm{TiO}_{2}-\mathrm{NaOAc}$ system, the (101) crystal facet of $\mathrm{TiO}_{2}$ is the most active crystal facet and the addition of alkali $\mathrm{NaOAc}$ enhances the catalytic activity with ethanol as the external hydrogen source. Control experiments suggest that photogenerated electrons play a unique role in this system.
Fig. 3 Calculated BDE of the two-step conversion strategy of the $\beta$-O-4 linkage in the lignin model. Reprinted with permission from Ref. [29]. Copyright 2018 American Chemical Society

\section{Two-step strategy:}

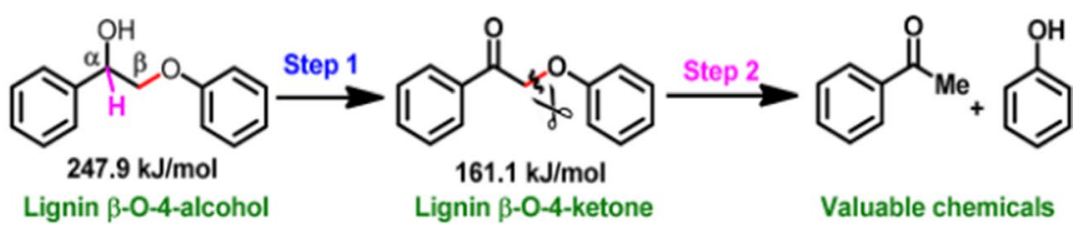

(a)

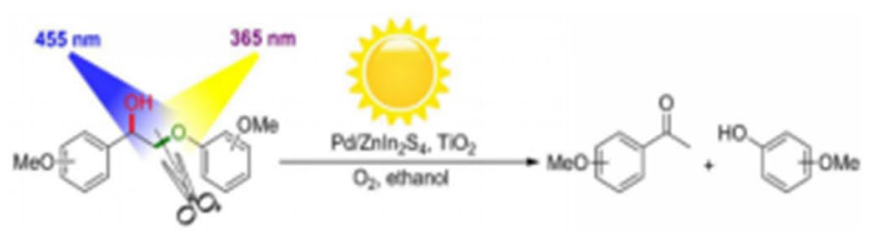

(c)

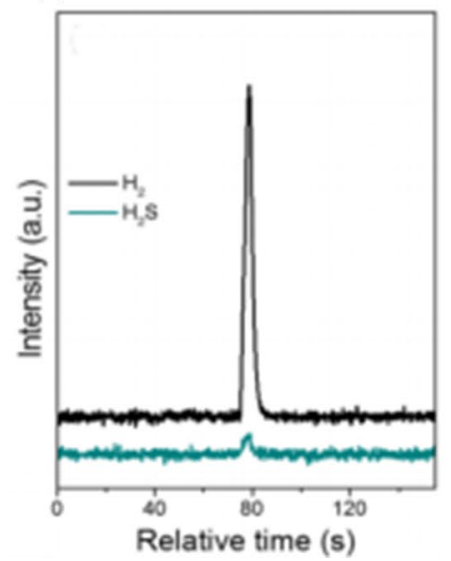

(d)

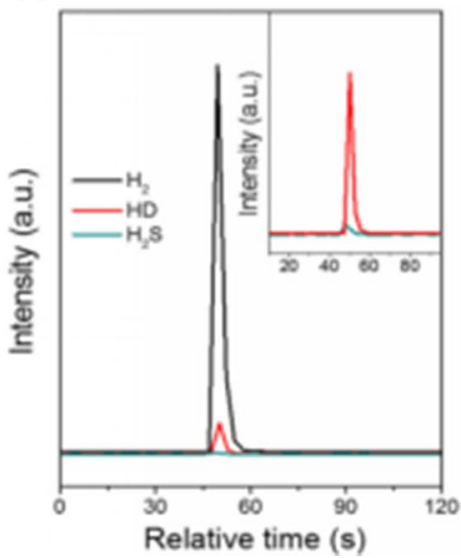

(b)

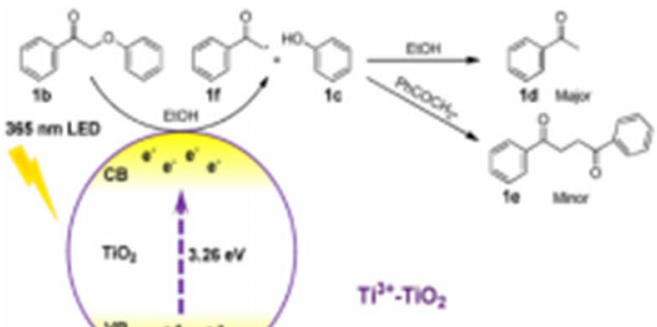

(e)

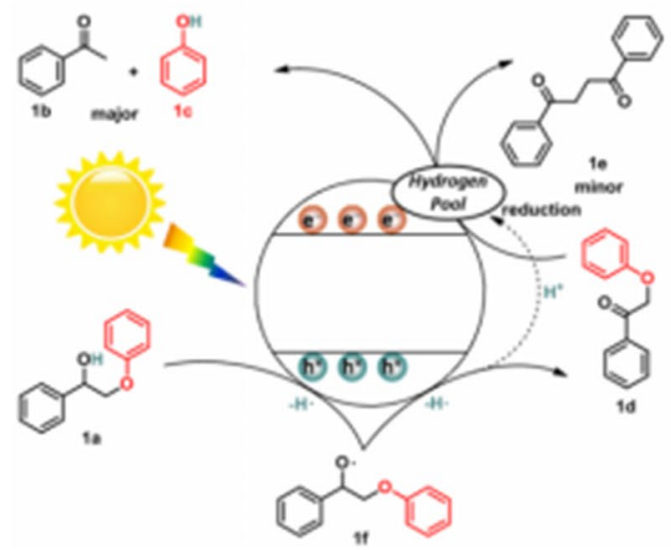

Fig. 4 a Illustration of the photocatalytic cleavage of $\beta-\mathrm{O}-4$ alcohols into phenol and acetophenone by oxidation-hydrogenolysis via the dual-wavelength switching strategy. b Possible reaction mechanism for photocatalytic $\mathrm{C}-\mathrm{O}$ bond cleavage of $\beta$-O-4 ketones over $\mathrm{TiO}_{2}$. Reprinted with permission from Ref. [30]. Copyright 2016 Ameri- can Chemical Society. c The gas phase fragmentation of PP-ol and d PP-ol- $\alpha \mathrm{CD}$ detected using mass spectrometry. e Schematic illustration of photocatalytic cleavage of the $\beta$-O- 4 bond via self-hydrogen transfer hydrogenolysis over $\mathrm{ZnIn}_{2} \mathrm{~S}_{4}$. Reprinted with permission from Ref. [31]. Copyright 2017 American Chemical Society 
The electrons reduce $\mathrm{Ti}^{4+}$ on the surface of $\mathrm{TiO}_{2}$ to $\mathrm{Ti}^{3+}$ instead of directly involving in cleaving the $\mathrm{C}-\mathrm{O}$ bond, and then the $\mathrm{Ti}^{3+}$ formed in situ adsorbs the substrate for weakening the $\mathrm{C}-\mathrm{O}$ bond to directly participate in cleaving the $\mathrm{C}-\mathrm{O}$ bond (Fig. $4 \mathrm{~b}$ ). This strategy not only integrates the oxidation-hydrogenation process in one pot by dual-wavelength variation but also obtains the aromatic monomers with superior yield.

Although this two-wavelength strategy achieves a onepot process, two catalysts are still required, and an external hydrogen donor is necessary. When alcohol is used as the hydrogen donor, the alcohol dehydrogenation product (aldehyde) may condense with phenol, making the product separation more complicated. To overcome this obstacle, Luo and coworkers [31] have extracted phenolic products from the $\beta$-O-4 lignin model phenoxy-1-phenylethanol (PP-ol) over $\mathrm{ZnIn}_{2} \mathrm{~S}_{4}$ to further integrate the dehydrogenation and hydrogenolysis reaction in one system, in which the alcoholic groups $\left(\mathrm{C}_{\alpha} \mathrm{H}-\mathrm{OH}\right)$ of $\mathrm{PP}-\mathrm{ol}$ serve as hydrogen donors to form a "hydrogen pool" on $\mathrm{ZnIn}_{2} \mathrm{~S}_{4}$ to produce phenolic compounds by self-hydrogen transfer. To ensure a pure self-hydrogen transfer mechanism, solvents without ability of hydrogen-donating (acetonitrile, acetone and tetrahydrofuran) are added to the reaction, obtaining a similar conversion (97-99\%) and moderate yield of cleaving $\beta$ O-4 bond products (phenol and acetophenone), which suggests that the conversion of the lignin model into aromatic chemicals indeed occurs through self-hydrogen transfer. Additionally, the detections of $\mathrm{H}_{2}$ and $\mathrm{H}_{2} \mathrm{~S}$ in the gas phase (Fig. 4c), which might originate from the hydrogen species of PP-ol, further prove the occurrence of self-hydrogen transfer hydrogenolysis. $\mathrm{H}_{2}$ and $\mathrm{HD}$ are detected by adding deuterated PP-ol (PP-ol- $\alpha \mathrm{CD})$ to the photocatalysis reaction (Fig. 4d), revealing that the $\mathrm{H}$-abstraction of the $\mathrm{C}_{\alpha} \mathrm{H}-\mathrm{OH}$ groups in PP-ol occurs on the surface of $\mathrm{ZnIn}_{2} \mathrm{~S}_{4}$. Based on the above results, a proposed mechanism for the fragmentation of the $\beta$-O-4 lignin model is outlined in Fig. 4e. $\mathrm{PP}-\mathrm{ol}$ undertakes $\mathrm{H}$-abstraction of $\alpha-\mathrm{OH}$ groups via photogenerated holes, resulting in the generation of $1 \mathrm{f}$ radicals. Thereafter, $\mathrm{H}$-abstraction of $\alpha-\mathrm{CH}$ groups leads to a yield of the $\beta$-O- 4 ketone intermediate. At the same time, the proton hydrogen adsorbed on the surface of $\mathrm{ZnIn}_{2} \mathrm{~S}_{4}$ reacts with photogenerated electrons to form a "hydrogen pool." When the $\beta$-O-4 ketone intermediate enters the "hydrogen pool", it generates the products of $\mathrm{C}-\mathrm{O}$ bond cleavage (phenol and acetophenone), while a small portion of the reduced hydrogen species combines to produce $\mathrm{H}_{2}$ accompanied by the formation of byproduct. This study opens a doorway to exploit renewable biofeedstock as well as solar energy to acquire phenolic compounds.

To efficiently use all three components of lignocellulose, Wu et al. [32] achieved lignin-first fractionation from birch woodmeal while retaining the hemicellulose and cellulose.
The results imply that the native lignin can be effectively converted into functionalized aromatic compounds using soluble colloidal CdS quantum dots (QDs) under mild conditions. Conversions of the solid residue, including cellulose and hemicellulose, are conducted after the separation of recolloidized CdS QDs. As disclosed in Fig. 5a, b, acidolysis is initially performed for the solid residue to obtain xylose under mild conditions (fraction I). Afterward, the remaining solid undergoes enzymatic hydrolysis to yield glucose (fraction II), demonstrating that the lignin-first concept for use of biomass can be integrated with the current biorefinery system without wrecking carbohydrate fractions. In addition, the mechanism for the fragmentation of the $\beta$-O- 4 lignin model is different from those of the previous two-step photocatalytic systems. The control experiments using either holes or electrons scavenger exhibit significantly decreased yields of aromatic fragments, confirming that photoexcited holes and electrons participate in the generation of acetophenone and phenol. The reaction is almost inhibited by adding 5,5-dimethyl-1-pyrroline-N-oxide (DMPO), indicating that the reaction proceeds via a free radical intermediate. Furthermore, when the $\mathrm{C}_{\alpha}$ hydrogen of benzyl group is replaced by a methyl group, the reaction barely occurs, suggesting that the presence of the $\mathrm{C}_{\alpha}$ hydrogen is critical for the reaction. Moreover, the generation of $\mathrm{C}_{\alpha}$ radicals has been confirmed via the spin trapping agent 5-diisopropoxyphosphoryl-5-methyl-1-pyrroline-N-oxide (DIPPMPO). Typically, free radicals can react with DIPPMPO to produce a nitroxide intermediate that undergoes disproportionation to form a correspondingly stable nitrone and hydroxylamine as the ultimate products (Fig. 5c) [33]. Positive ion electrospray ionization mass spectrometry of the product mixture after adding DIPPMPO clearly proves the formation of $\mathrm{C}_{\alpha}$ radicals (Fig. 5d) [34]. As depicted in Fig. 5e, a main signal at $28.7 \mathrm{ppm}$, which is index to $\mathrm{C}_{\alpha}$ radical adducts [33], appears in the ${ }^{31} \mathrm{P}$ nuclear magnetic resonance (NMR) spectrum, further demonstrating that the $\mathrm{C}_{\alpha}$ radical is essential for this system. Based on the above analysis, an electron-hole coupled (EHCO) mechanism is illustrated in Fig. 5f, in which the oxidative dehydrogenation $(\mathrm{ODH})$ of the $\mathrm{C}_{\alpha}-\mathrm{H}$ bond triggered by holes first occurs to produce the $\mathrm{C}_{\alpha}$ radical intermediate, and then this intermediate undertakes the cleavage of the $\beta$-O- 4 bond driven by the electron.

\section{C-C Bond Cleavage}

Much effort has been devoted to cracking the $\mathrm{C}-\mathrm{O}$ bonds in lignin into valuable aromatic products, but selective $\mathrm{C}-\mathrm{C}$ bond cleavage in macromolecular biomass under mild conditions remains a challenge. When a $\mathrm{C}-\mathrm{C}$ bond is a targeted linkage to be fragmented, $\mathrm{C}_{\beta}-\mathrm{H}$ bond activation is necessary [35]. However, once the $\mathrm{C}-\mathrm{OH}$ bond is transferred to a ketone by oxy-dehydrogenation, the $\mathrm{BDE}$ of the $\mathrm{C}_{\alpha}-\mathrm{C}_{\beta}$ 
(a)

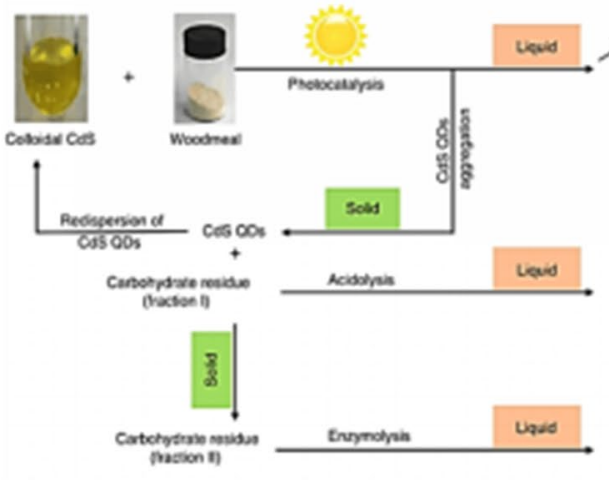

(c)

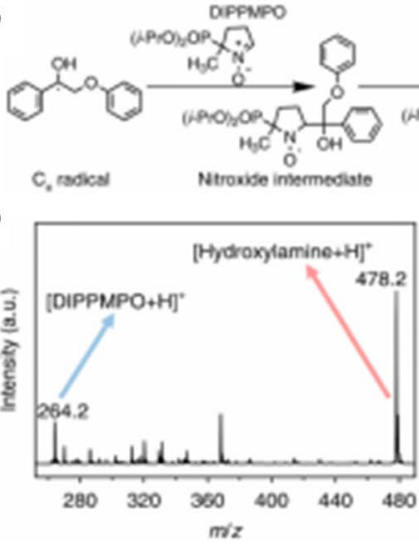

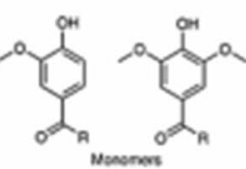
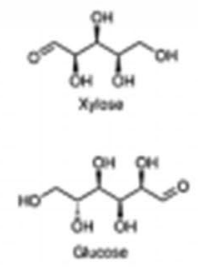

soose

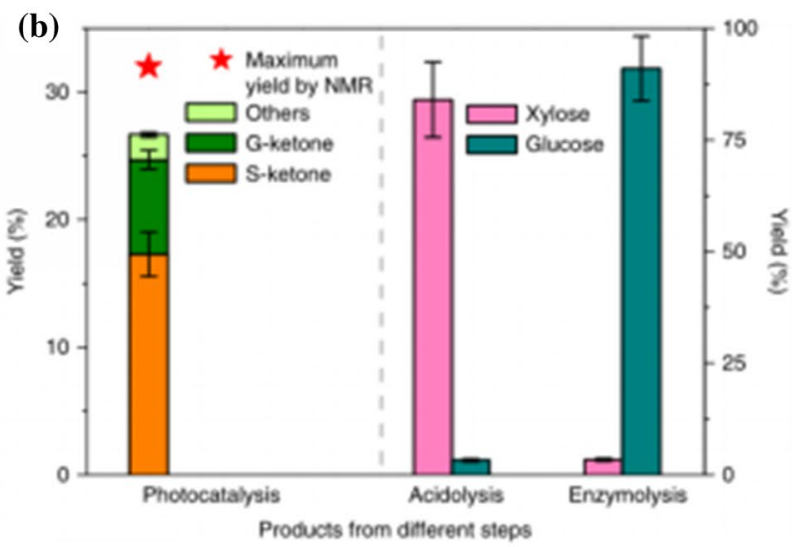

(f)

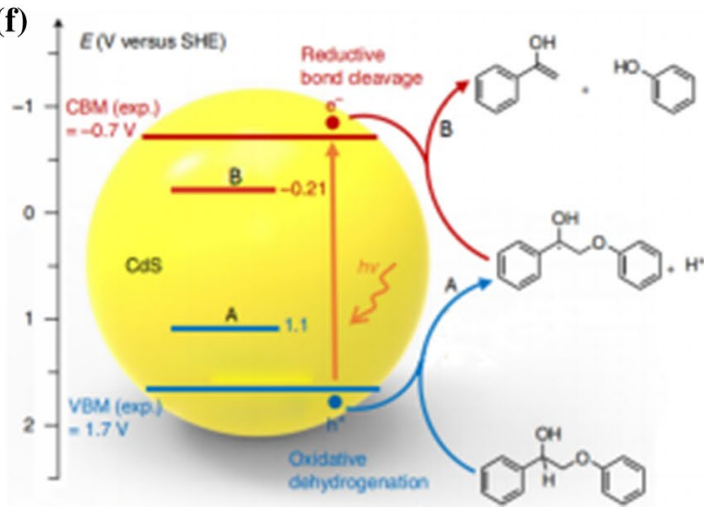

Fig. 5 a Illustration of the entire process for visible-light-driven lignin-first conversion of birch woodmeal. b Yields of products obtained in photocatalysis, acidolysis and enzymolysis. c Spin trapping reaction of the $\mathrm{C}_{\alpha}$ radical and DIPPMPO. d Positive-ion electrospray ionization mass spectrum and $\mathbf{e}^{31} \mathrm{P}$ NMR spectrum of the product mixture by adding DIPPMPO. f Illustration of the photocatalytic cleavage of the $\beta-\mathrm{O}-4$ bond in PP-ol via an electron-hole coupled mechanism (A and B denote the potential for oxidative dehydrogenation of PP-ol and the potential for reductive cleavage of the $\beta$-O-4 bond in the $\mathrm{C}_{\alpha}$ radical intermediate against the positions of $\mathrm{VBM}$ and $\mathrm{CBM}$ of CdS, respectively. VBM and CBM denote the valence band maximum and conduction band minimum). Reprinted with permission from Ref. [32]. Copyright 2018 Nature Catalysis

lower than that of blank $\mathrm{CeO}_{2}(2.86 \mathrm{eV})$, indicating that the presence of $\mathrm{Ce}^{3+}$ can narrow the band gap of $\mathrm{CeO}_{2}$. Furthermore, theoretical calculations demonstrate that the introduction of $\mathrm{CuO}_{x}$ clusters moves the valence band edge of titanium dioxide to a higher energy position, thereby inhibiting the side reaction of the oxygen dehydrogenation to enhance the selectivity of benzaldehydes.

Selective $\mathrm{C}-\mathrm{C}$ bond cleavage in lignin affords useful and functional fine aromatic chemicals [41], and the interaction between the catalyst surface and lignin substrate also has a great effect on the conversion of lignin. Liu et al. [42] have used two-dimensional flexible graphite phase carbon nitride $\left(\mathrm{g}-\mathrm{C}_{3} \mathrm{~N}_{4}\right)$ to provide an ideal surface for the adsorption of lignin models. The $\mathrm{g}-\mathrm{C}_{3} \mathrm{~N}_{4}$ prepared from melamine $\left(\mathrm{C}_{3} \mathrm{~N}_{4}-\mathrm{M}\right)$ and urea $\left(\mathrm{C}_{3} \mathrm{~N}_{4}-\mathrm{U}\right)$ is synthesized to investigate the effect on photoactivity with different precursors. Herein, $\mathrm{C}_{3} \mathrm{~N}_{4}-\mathrm{U}$ exhibits higher $\mathrm{C}-\mathrm{C}$ cleavage activity than $\mathrm{C}_{3} \mathrm{~N}_{4}-\mathrm{M}$, which is due to a larger surface area and the faster carrier transport of $\mathrm{C}_{3} \mathrm{~N}_{4}-\mathrm{U}$ [43]. When the mesoporous graphitic 
(a)

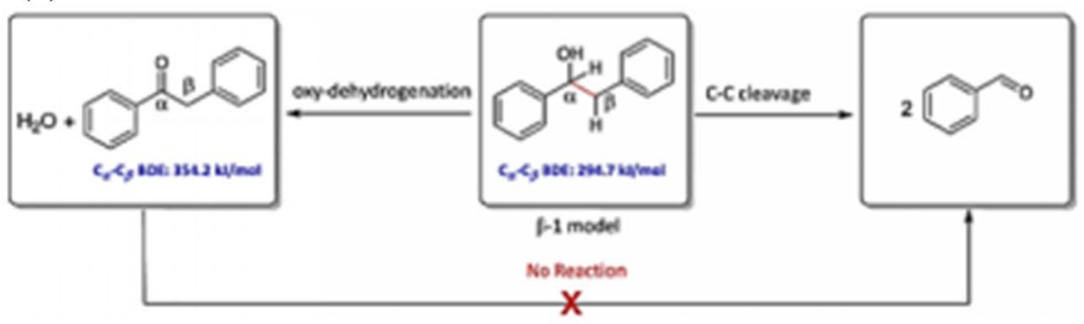

(c)

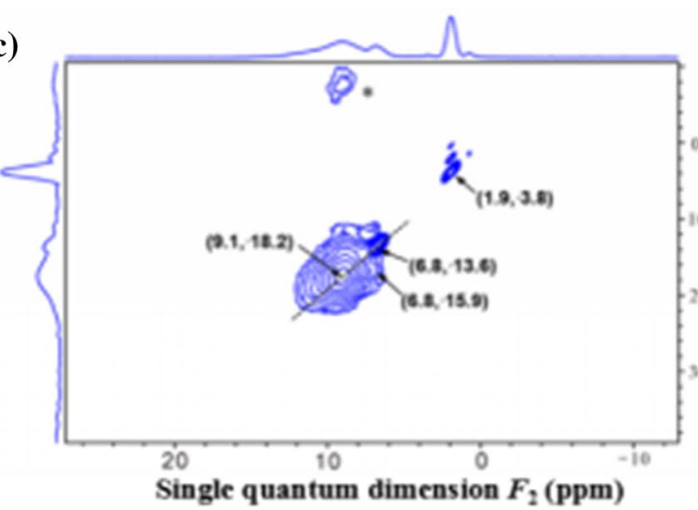

Fig. 6 a Schematic illustration of two competing reactions for oxydehydrogenation and $\mathrm{C}-\mathrm{C}$ cleavage in the oxidation of the $\beta-1$ model. b Optical adsorption edges of the $\mathrm{CuO}_{x} / \mathrm{CeO}_{2} / \mathrm{A}-\mathrm{NT}, \mathrm{CuO}_{x} / \mathrm{A}-\mathrm{NT}$, $\mathrm{CeO}_{2} / \mathrm{A}-\mathrm{NT}, \mathrm{A}-\mathrm{NT}$, and $\mathrm{CeO}_{2}$ photocatalysts, respectively. Reprinted with permission from Ref. [36]. Copyright 2017 American Chemi-

carbon nitride (mpg- $\mathrm{C}_{3} \mathrm{~N}_{4}$ ) is used, the lignin model substrate is nearly completely transformed. The solid-state NMR techniques and density functional theory (DFT) calculations jointly verify $\pi-\pi$ stacking interactions between the mpg- $\mathrm{C}_{3} \mathrm{~N}_{4}$ and lignin models. As shown in Fig. $6 \mathrm{c}$, the off-diagonal peak pair appears at $(6.8,15.9) \mathrm{ppm}$ in the twodimensional hydrogen double quantum magic angle spinning nuclear magnetic resonance (2D ${ }^{1} \mathrm{H}-{ }^{1} \mathrm{H}$ DQ MAS NMR) spectrum, indicating the spatial proximity of the hydrogen on the benzene ring of the substrate to the $\mathrm{NH}_{x}$ group in mpg- $\mathrm{C}_{3} \mathrm{~N}_{4}$ [44], which facilitates the transfer of photogenerated holes and promotes the photocatalytic reactions. DFT establishes a corrugated $\mathrm{C}_{3} \mathrm{~N}_{4}$ surface with an adsorption energy of $-0.92 \mathrm{eV}$ and is parallel to two benzene rings of the substrate molecule (Fig. 6d). The distance between triazine rings and benzene rings is $3.2-3.9 \AA$, corresponding to the range of $\pi-\pi$ stacking interactions, which contributes to the molecular activation $[45,46]$ and further promotes the conversion of the lignin model molecule.

In addition to semiconductor-based catalysts, quinones, as organic oxidants with excellent oxidation ability, are also used to promote the depolymerization of lignin. Mitchell and coworkers [47] have evaluated the photocatalytic C-C (b)

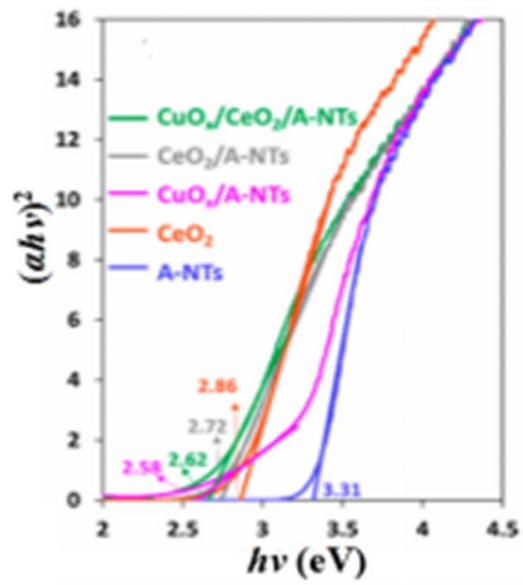

(d)

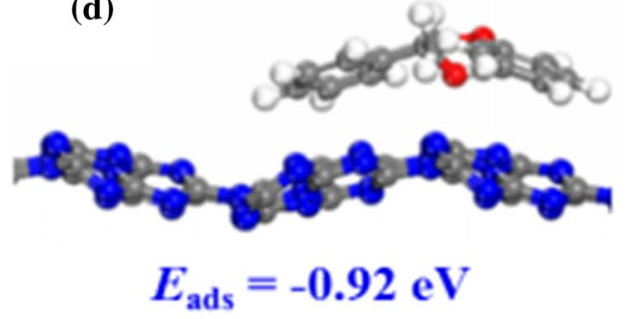

cal Society. c $2 \mathrm{D}{ }^{1} \mathrm{H}-{ }^{1} \mathrm{H}$ DQ MAS NMR spectrum of mpg- $\mathrm{C}_{3} \mathrm{~N}_{4}$ (* denotes a spinning sideband). d Separation distance and adsorption energy between the substrate and $\mathrm{C}_{3} \mathrm{~N}_{4}$ surface. Reprinted with permission from Ref. [42]. Copyright 2018 American Chemical Society

bond scission of lignin models using the simpler and cheaper 1,4-benzoquinone (BQ) with copper nanoparticles as the electron transfer mediator (ETM) under oxygen atmosphere, in which $\mathrm{BQ}$ is formed by in situ oxidation of 1,4-hydroquinone $\left(\mathrm{BQH}_{2}\right)$, and oxygen is used as a terminal oxidant. The cleavage of the $\mathrm{C}-\mathrm{C}$ bond might occur by $\mathrm{H}$-abstraction from the $\mathrm{O}-\mathrm{H}$ bond by the photoexcited triplet quinone $\left({ }^{3} \mathrm{BQ}\right)$ to form an alkoxy radical intermediate, and then this alkoxy radical is subjected to $\mathrm{C}-\mathrm{C}$ homolytic fragmentation to form a new alkyl radical and aldehyde (Fig. 7). Finally, two carbonyl compounds are obtained by $\mathrm{C}-\mathrm{C}$ cleavage reaction via a radical process. In addition, this methodology has been expanded to a range of $\beta$-O-4 lignin model compounds by effectively using visible light, leading to the production of a series of aromatic products.

\section{Photocatalytic Conversion of Biomass-Relevant Alcohols}

In addition to lignocellulosic biomass, photocatalytic transformation of biomass-relevant alcohols is highly appealing for obtaining usable chemicals [48-50], which are pivotal 


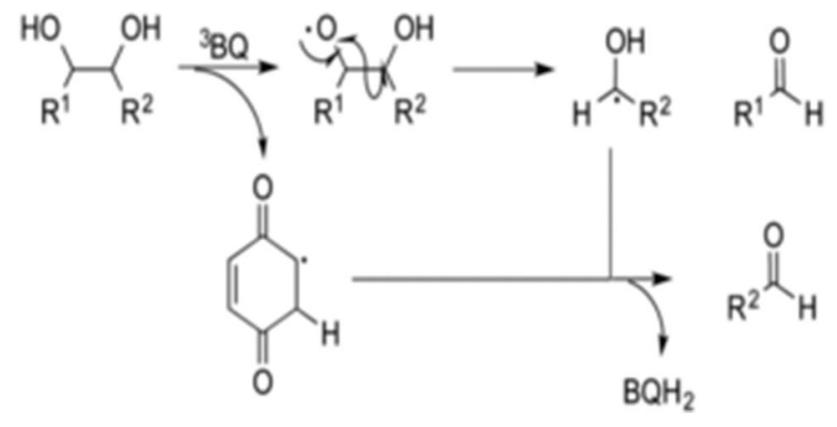

Fig. 7 Proposed mechanistic pathways of $\mathrm{C}-\mathrm{C}$ bond cleavage in the lignin model via $\mathrm{BQH}_{2}$. Reprinted with permission from Ref. [47]. Copyright 2014 American Chemical Society

intermediates for the manufacture of pharmaceuticals, confectionery fragrances and biopolymers $[10,51]$. Hence, we concisely summarize the recent overview of selective photocatalytic conversion of biomass-relevant alcohols in this section, including photooxidation of biomass-relevant alcohols, visible-light-induced hydrogenation of biomassderived 5-hydroxymethylfurfural (HMF) and photoredoxcatalyzed conversion of biomass-relevant alcohols integrated with hydrogen $\left(\mathrm{H}_{2}\right)$ evolution.

\section{Mechanisms for the Photocatalytic Conversion of Biomass-Relevant Alcohols}

Photocatalytic conversion of biomass-relevant alcohols can be performed under aerobic or anaerobic conditions. In aerobic atmosphere (Fig. 8a), oxygen molecules are reduced to reactive oxygen species, such as the superoxide radical $\left(\mathrm{O}_{2}^{-}\right)$and singlet molecular oxygen $\left({ }^{1} \mathrm{O}_{2}\right)$, by the photoexcited electrons in the conduction band (CB). These species subsequently participate in the transformation of biomass derivatives [48]. Meanwhile, holes accumulated in the valence band (VB) can oxidize biomass-derived alcohols to the corresponding carbonyl compound. By contrast, under anaerobic conditions (Fig. 8b), the photogenerated electrons are available for reducing protons to produce $\mathrm{H}_{2}$, while biomass-relevant alcohols can be oxidized by photoinduced holes, realizing the simultaneous use of electrons and holes.

\section{Photocatalytic Conversion of HMF}

\section{Selective Oxidation of HMF}

A summary of the recent advances in selective photoredoxcatalyzed biomass-relevant alcohols conversion is outlined in Table 1. HMF, as one of the representatives of biomass intermediates, can be oxidized to many species containing polymeric precursors, such as 2,5-furandicarboxylic acid (FDCA) and 2,5-diformylfuran (DFF) [52]. FDCA plays a key role in commerce, because it is the alternative to terephthalic acid in the production of polyesters, polyurethanes and polyamides [11]. For instance, Xu et al. [53] have constructed a photocatalyst of cobalt thioporphyrazine $(\mathrm{CoPz})$ bonded on $\mathrm{g}-\mathrm{C}_{3} \mathrm{~N}_{4}\left(\mathrm{CoPz} / \mathrm{g}-\mathrm{C}_{3} \mathrm{~N}_{4}\right)$, which possesses a highly efficient photocatalytic performance for selective transformation of HMF into FDCA under aerobic conditions. Because of the powerful interaction between $\mathrm{g}-\mathrm{C}_{3} \mathrm{~N}_{4}$ and $\mathrm{CoPz}$, an optimal FDCA yield of $96.1 \%$ is achieved after $22 \mathrm{~h}$ of irradiation in basic conditions. Although a high $\mathrm{HMF}(99.6 \%)$ conversion is obtained on bare $\mathrm{g}-\mathrm{C}_{3} \mathrm{~N}_{4}$ catalyst under the same conditions, no liquid products are detected, indicating that $\mathrm{HMF}$ is likely to mineralize into $\mathrm{H}_{2} \mathrm{O}$ and $\mathrm{CO}_{2}$ on bare $\mathrm{g}-\mathrm{C}_{3} \mathrm{~N}_{4}$. Furthermore, the electron paramagnetic resonance (EPR) technique using 2,2,6,6-tetramethylpiperidine (TMP) and 5,5-dimethyl-1-pyrroline-N-oxide (DMPO) as spin-trapping regents is used to monitor oxidative species in the reaction. As disclosed in Fig. 9a, remarkable EPR signals for ${ }^{1} \mathrm{O}_{2}$-TMP adducts are observed over $\mathrm{CoPz} / \mathrm{g}-\mathrm{C}_{3} \mathrm{~N}_{4}$ irradiated by a pulsed laser and are assigned to the nitroxide produced by the reaction of TMP and ${ }^{1} \mathrm{O}_{2}$ [54]. However, a characteristic quartet signal of DMPO-hydroxyl radical ( $\mathrm{HO}$ ) adducts is detected over bare $\mathrm{g}_{-} \mathrm{C}_{3} \mathrm{~N}_{4}$ by adding DMPO to the reaction [55]. The above results further show that, compared with bare $\mathrm{g}-\mathrm{C}_{3} \mathrm{~N}_{4}, \mathrm{CoPz} / \mathrm{g}-\mathrm{C}_{3} \mathrm{~N}_{4}$ has a suitable oxidation capacity to selectively oxidize HMF into FDCA instead of undertaking photocatalytic mineralization.
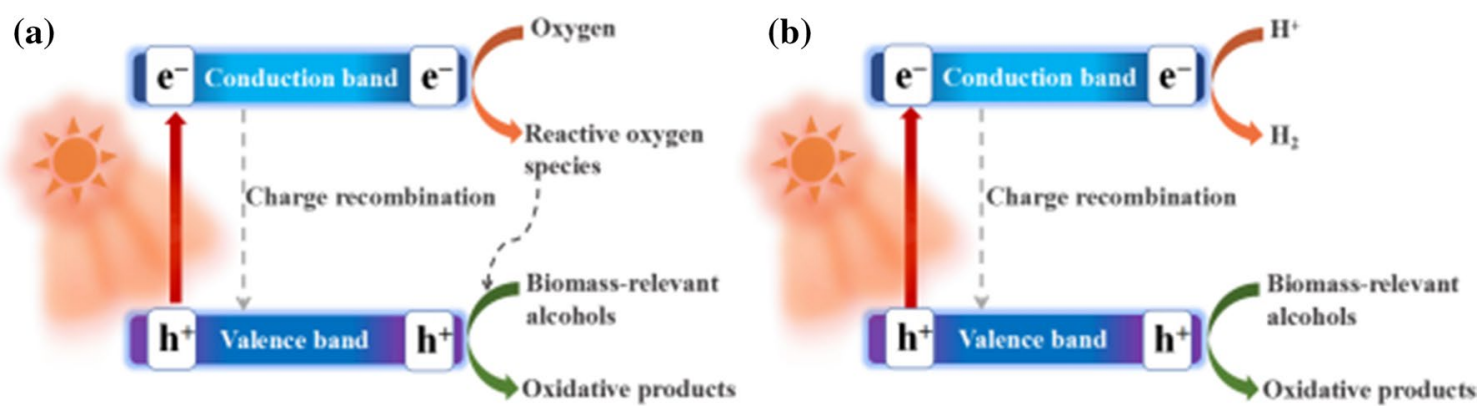

Fig. 8 Illustration of mechanisms for the photocatalytic conversion of biomass-relevant alcohols under $\mathbf{a}$ aerobic and $\mathbf{b}$ anaerobic conditions 
Table 1 An overview of the recent literature for biomass-relevant alcohols conversion

\begin{tabular}{|c|c|c|c|c|c|c|c|}
\hline Entry & Photocatalysts & Substrate & Solvent & Atmosphere & Product & Light source & Ref. \\
\hline 1 & $\mathrm{Nb}_{2} \mathrm{O}_{5}-800$ & $\mathrm{HMF}$ & BTF & $\mathrm{O}_{2}$ & DFF & $300 \mathrm{~W}$ Xe lamp, > $400 \mathrm{~nm}$ & {$[58]$} \\
\hline 2 & $\mathrm{Pt} / \mathrm{SGCN}$ & HMF & $\mathrm{H}_{2} \mathrm{O}$ & $\mathrm{N}_{2}$ & DFF and $\mathrm{H}_{2}$ & LED lamp, > $400 \mathrm{~nm}$ & {$[62]$} \\
\hline 3 & $\mathrm{~g}-\mathrm{C}_{3} \mathrm{~N}_{4}$ & HMF & $\mathrm{H}_{2} \mathrm{O}$ & $\mathrm{N}_{2}$ & DFF and FDCA & $15 \mathrm{~W}$ FL lamp, 340-420 nm & {$[10]$} \\
\hline 4 & $\mathrm{Ni} / \mathrm{CdS}$ & HMF or FA & $\mathrm{H}_{2} \mathrm{O}$ & $\mathrm{N}_{2}$ & DFF or Furfural, $\mathrm{H}_{2}$ & Blue LED lamp, $450 \mathrm{~nm}$ & {$[13]$} \\
\hline 5 & $\mathrm{Au}-\mathrm{Ru} / \mathrm{rGO}$ & HMF & Toluene & $\mathrm{O}_{2}$ & DFF & 300 W Xe lamp & {$[57]$} \\
\hline 6 & $\mathrm{Zn}_{x} \mathrm{Cd}_{1-x} \mathrm{~S}-\mathrm{P}$ & HMF & $\mathrm{H}_{2} \mathrm{O}$ & $\mathrm{Ar}$ & DFF and $\mathrm{H}_{2}$ & White LED lamp & [84] \\
\hline 7 & $\mathrm{Pt} / \mathrm{g}-\mathrm{C}_{3} \mathrm{~N}_{4}$ & HMF & $\mathrm{H}_{2} \mathrm{O}$ & Air & DHMF & $210 \mathrm{~W}$ Xe lamp, $\geq 420 \mathrm{~nm}$ & {$[64]$} \\
\hline 8 & $\mathrm{Pd} / \mathrm{MIL}-101(\mathrm{Fe})-\mathrm{NH}_{2}$ & HMF & $\mathrm{CH}_{3} \mathrm{CN}$ & Air & DHMF & $300 \mathrm{~W}$ Xe lamp, $\geq 420 \mathrm{~nm}$ & {$[67]$} \\
\hline 9 & $\mathrm{Ti}_{3} \mathrm{C}_{2} \mathrm{~T}_{x} / \mathrm{CdS}$ & FA & $\mathrm{H}_{2} \mathrm{O}$ & $\mathrm{N}_{2}$ & Furfural and $\mathrm{H}_{2}$ & $300 \mathrm{~W}$ Xe lamp, > $420 \mathrm{~nm}$ & {$[68]$} \\
\hline 10 & $\mathrm{Co} / \mathrm{CdS}$ & BA & $\mathrm{CH}_{3} \mathrm{CN}$ & $\mathrm{N}_{2}$ & BAD and $\mathrm{H}_{2}$ & $300 \mathrm{~W}$ Xe lamp, $\geq 420 \mathrm{~nm}$ & {$[14]$} \\
\hline 11 & $\mathrm{Ni}_{x} \mathrm{~S}_{y} / \mathrm{ZnS}$ & BA & $\mathrm{H}_{2} \mathrm{O}$ & $\mathrm{N}_{2}$ & BAD and $\mathrm{H}_{2}$ & $500 \mathrm{~W}$ Xe lamp, > $200 \mathrm{~nm}$ & {$[85]$} \\
\hline 12 & $\mathrm{Ni}_{2} \mathrm{P}$-graphene- $\mathrm{TiO}_{2}$ & BA & $\mathrm{H}_{2} \mathrm{O}$ & $\mathrm{N}_{2}$ & BAD and $\mathrm{H}_{2}$ & $300 \mathrm{~W}$ Xe lamp, $\geq 420 \mathrm{~nm}$ & [86] \\
\hline 13 & $\mathrm{CoP} / \mathrm{CdS}$ & BA & $\mathrm{H}_{2} \mathrm{O}$ & $\mathrm{N}_{2}$ & BAD and $\mathrm{H}_{2}$ & White LED lamp, $\geq 420 \mathrm{~nm}$ & {$[15]$} \\
\hline 14 & Carbon nitride aerogel & $\mathrm{BA}$ & $\mathrm{CH}_{3} \mathrm{CN}$ & $\mathrm{O}_{2}$ & BAD & $300 \mathrm{~W}$ Xe lamp, $\geq 420 \mathrm{~nm}$ & [87] \\
\hline
\end{tabular}

$H M F$ 5-hydroxymethylfurfural; $B T F$ benzotrifluoride; $D F F$ 2,5-diformylfuran; $S G C N$ porous carbon nitride; $F D C A$ 2,5-furandicarboxylic acid; $F L$ fluorescent; $F A$ furfural alcohol; $r G O$ reduced graphene oxides; $D H M F$ 2,5-dihydroxymethylfuran; $B A$ benzyl alcohol; $B A D$ benzaldehyde

(a)

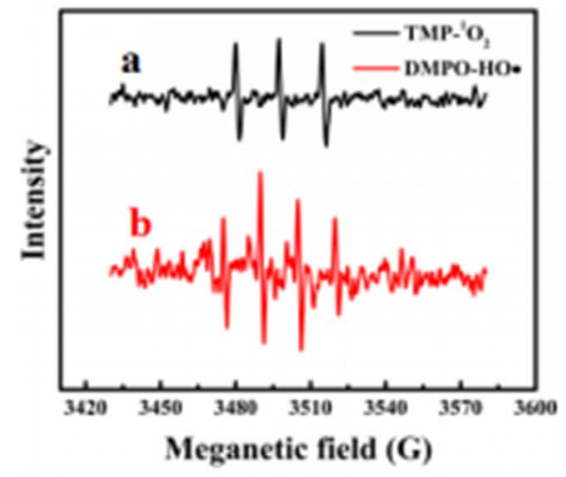

(b)

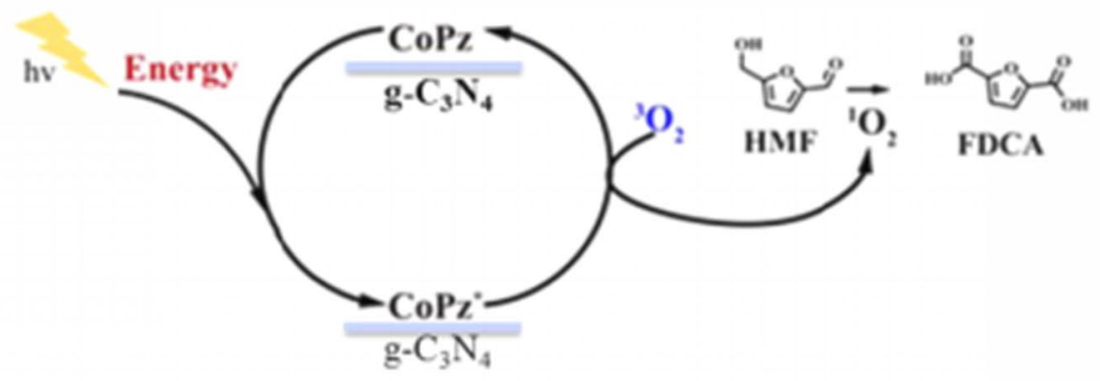

(c)

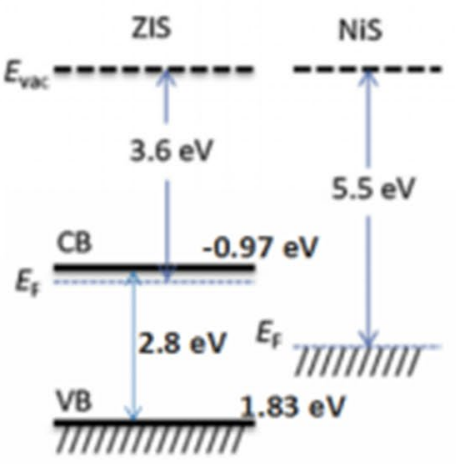

(d)

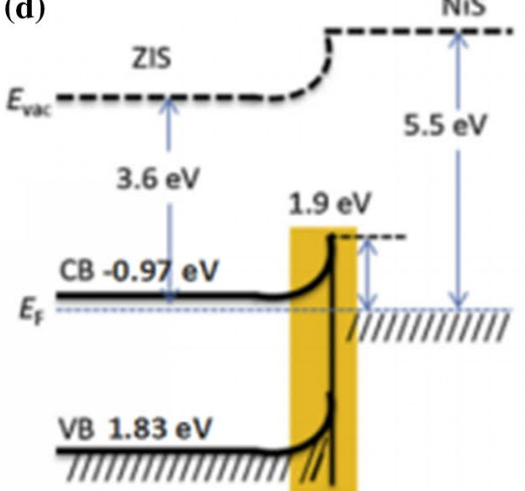

(e)

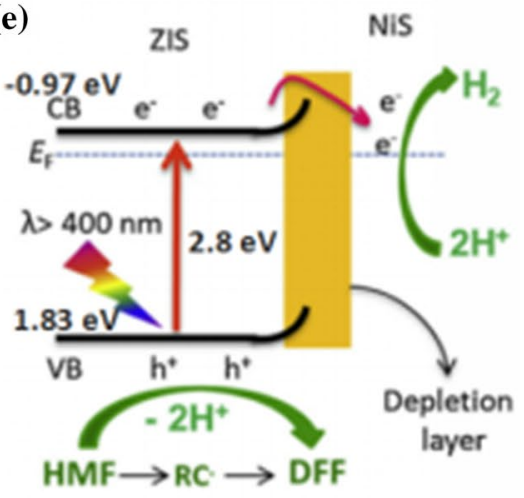

Fig. 9 a EPR signals of (a) the DMPO-HO adduct of bare $\mathrm{g}_{-} \mathrm{C}_{3} \mathrm{~N}_{4}$ in water and (b) the TMP- ${ }^{1} \mathrm{O}_{2}$ adduct of $\mathrm{CoPz} / \mathrm{g}-\mathrm{C}_{3} \mathrm{~N}_{4}$ in water under light irradiation. b Possible mechanism for photocatalytic oxidation of HMF into FDCA with the $\mathrm{CoPz} / \mathrm{g}-\mathrm{C}_{3} \mathrm{~N}_{4}$ catalyst. Reprinted with permission from Ref. [53]. Copyright 2017 American Chemical Society. Illustration of energy levels for $\mathrm{Zn}_{3} \mathrm{In}_{2} \mathrm{~S}_{6}$ and $\mathrm{NiS}$ c before and d after interfacing $\left(E_{\mathrm{vac}}, E_{\mathrm{F}}, \mathrm{CB}\right.$ and $\mathrm{VB}$ denote the vacuum level, Fermi level, conduction band and valence band, respectively). e Schematic diagram of the dual-function photocatalytic reaction mechanism for selective oxidation of HMF to $\mathrm{H}_{2}$ and DFF $\left(\mathrm{e}^{-}\right.$and $\mathrm{h}^{+}$are photogenerated electrons and holes, respectively). Reprinted with permission from Ref. [59]. Copyright 2020 Elsevier 
Figure $9 \mathrm{~b}$ displays the photocatalytic mechanism of HMF conversion over CoPz/g- $\mathrm{C}_{3} \mathrm{~N}_{4}$. Upon visible light irradiation, the $\mathrm{CoPz}$ dispersed on $\mathrm{g}-\mathrm{C}_{3} \mathrm{~N}_{4}$ transforms triplet $\mathrm{O}_{2}$ $\left({ }^{3} \mathrm{O}_{2}\right)$ into ${ }^{1} \mathrm{O}_{2}$ by the energy transition, and the appropriate oxidation potential of ${ }^{1} \mathrm{O}_{2}$ can selectively convert $\mathrm{HMF}$ to the target product FDCA.

HMF as a hygroscopic compound easily undergoes intermolecular etherification to form a HMF-dimer [56]. However, it can be used as a beneficial starting compound to yield usable and stable DFF. The target product DFF is widely used to manufacture the intermediates of pharmaceuticals, antifungal agents, ligands, and nematocides [57]. $\mathrm{Nb}_{2} \mathrm{O}_{5}$ catalyst calcined at $800{ }^{\circ} \mathrm{C}\left(\mathrm{Nb}_{2} \mathrm{O}_{5}-800\right)$ has been used for photocatalytic selective oxidation of HMF and shows an excellent DFF selectivity (90.6\%) in HMF-containing benzotrifluoride (BTF) solvent under aerobic condition with visible light irradiation (Table 1, entry 1) [58]. Although the band-gap energy of $\mathrm{Nb}_{2} \mathrm{O}_{5}$ exceeds $3.2 \mathrm{eV}$, the selective HMF oxidation can occur under visible light, which might be attributed to the generation of visible-light-responsive alcoholate species between $\mathrm{HMF}$ and $\mathrm{Nb}_{2} \mathrm{O}_{5}$. To identify the main active species in this reaction, a benzoquinone scavenger for $\mathrm{O}_{2}{ }^{-}$or isopropanol scavenger for $\mathrm{OH}$ is added to the reaction. The results show that no substantial effect on the performance is detected, revealing that neither $\mathrm{O}_{2}{ }^{-}$nor ${ }^{\circ} \mathrm{OH}$ is the dominant active species for the reaction. In contrast, the photocatalytic performance remarkably decreases with the addition of a hole scavenger (ethylenediaminetetraacetic acid), suggesting that the photogenerated hole has an important effect on the photocatalytic process.

\section{HMF Oxidation Coupled with Photocatalytic $\mathrm{H}_{2}$ Generation}

A dual-function photocatalytic reaction for selective oxidation of biomass-relevant alcohols into clean energy and useful fine chemicals can be conducted in one pot to simultaneously use photogenerated electrons and holes. Noble metal-free 2D/2D$3 \mathrm{D} \mathrm{NiS} / \mathrm{Zn}_{3} \mathrm{In}_{2} \mathrm{~S}_{6}$ composites have been fabricated via a onestep approach for efficient transformation of HMF into DFF and $\mathrm{H}_{2}$ with high selectivity under visible light [59]. As shown in Fig. 9c, the VB potential of $\mathrm{Zn}_{3} \mathrm{In}_{2} \mathrm{~S}_{6}$ is estimated to be $1.83 \mathrm{eV}$. The optical band-gap energy of $\mathrm{Zn}_{3} \mathrm{In}_{2} \mathrm{~S}_{6}$ is calculated to be $2.80 \mathrm{eV}$ based on the Kubelka-Munk function, and thus the $\mathrm{CB}$ potential of $\mathrm{Zn}_{3} \mathrm{In}_{2} \mathrm{~S}_{6}$ is determined as $-0.97 \mathrm{eV}$. The work function of $\mathrm{NiS}(5.5 \mathrm{eV})$ is higher than that of $\mathrm{Zn}_{3} \mathrm{In}_{2} \mathrm{~S}_{6}$ (3.6 eV) [60, 61]. Consequently, when $\mathrm{Zn}_{3} \mathrm{In}_{2} \mathrm{~S}_{6}$ and NiS contact intimately, a barrier region is established in the contact interface (yellow rectangle in Fig. 9d), so that the photoexcited electrons in $\mathrm{Zn}_{3} \mathrm{In}_{2} \mathrm{~S}_{6}$ can spontaneously transfer to NiS across the interface (Fig. 9e), thereby contributing to the separation and migration of photogenerated charge carriers. HMF can be converted to DFF and $\mathrm{H}^{+}$by holes of $\mathrm{Zn}_{3} \mathrm{In}_{2} \mathrm{~S}_{6}$, while the electrons can react with $\mathrm{H}^{+}$on the NiS surface to form $\mathrm{H}_{2}$. Hence, a cyclic and efficient reaction toward solar-to-chemical energy transformation of biomass-relevant feedstocks is running. Additionally, Pt modified porous carbon nitride (SGCN) has been synthesized by a combined sol-gel/thermal condensation approach and applied to photoredox-catalyzed HMF oxidation coupled with $\mathrm{H}_{2}$ production (Table 1, entry 2) [62]. Because of the appropriate VBM of SGCN, the unselective $\mathrm{OH}$ radicals cannot be generated, thereby inhibiting the over-oxidation or photocatalytic mineralization.

\section{Photocatalytic Hydrogenation of HMF}

Notably, hydrogenation of HMF can obtain various valuable fine chemicals, such as 2,5-dihydroxymethylfuran (DHMF), 2,5-dimethyltetrahydrofuran (DMTHF) and 2,5-dihydroxymethyl-tetrahydrofuran (DHMTHF) [52, 63]. Among them, DHMF has been used not only in the synthesis of drugs but also in the production of resins, polymers and artificial fibers [52]. In this scenario, $\mathrm{Pt} / \mathrm{g}-\mathrm{C}_{3} \mathrm{~N}_{4}$ has been synthesized for photocatalytic hydrogenation of HMF to DHMF under visible light with trimethylamine (TEA) as a sacrificial electron donor (Table 1, entry 7) [64]. In this system, the doped Pt promotes $\mathrm{H}_{2}$ evolution from water, and then the formed $\mathrm{H}_{2}$ partakes in the reduction of HMF to yield DHMF. Compared with other metal-doped g- $\mathrm{C}_{3} \mathrm{~N}_{4}\left(\mathrm{M} / \mathrm{g}-\mathrm{C}_{3} \mathrm{~N}_{4}, \mathrm{M}=\mathrm{Zn}, \mathrm{Ni}, \mathrm{Cu}\right.$, $\mathrm{Co}, \mathrm{La}, \mathrm{Ce}), \mathrm{Pt} / \mathrm{g}-\mathrm{C}_{3} \mathrm{~N}_{4}$ exhibits the best performance for $\mathrm{HMF}$ hydrogenation. Because of its high work function, Pt can efficiently trap electrons from the $\mathrm{CB}$ of excited $\mathrm{g}_{-} \mathrm{C}_{3} \mathrm{~N}_{4}$, which facilitates the separation of the photogenerated electron-hole pairs [65, 66], resulting in the enhanced photoactivity of HMF hydrogenation.

In another example, Pd nanoparticles supported on aminefunctionalized iron-based metal-organic frameworks ( $\mathrm{Pd} /$ MIL-101(Fe)- $\mathrm{NH}_{2}$ ) have been prepared by Dong and coworkers [67] for visible-light-induced transfer hydrogenation of HMF to DHMF with triethylamine-formic acid (TEA$\mathrm{HCOOH}$ ) as the hydrogen source (Table 1, entry 8). In comparison, Pd deposited metal-organic frameworks samples without amine group modification exhibit insufficient activity toward visible-light-induced transfer hydrogenation reactions, indicating that the amine group plays a unique role in the photocatalytic hydrogenation. DFT studies demonstrate that the amine group not only stabilizes Pd nanoparticles in Pd/MIL$101(\mathrm{Fe})-\mathrm{NH}_{2}$ but also enhances the electron density of the $\mathrm{Pd}$ center upon light adsorption, thereby promoting biomassbased HMF hydrogenation.

\section{Photocatalytic Conversion of Furfural Alcohol (FA)}

\section{Selective Oxidation of FA}

FA is a sustainable candidate for biofuels and high valueadded fine chemicals, because it can be used as a starting 
feedstock for the synthesis of ethyl levulinate, furfural, furoic acid, pentanediol, etc. [68]. In this regard, $\mathrm{H}_{1.4} \mathrm{Ti}_{1.65} \mathrm{O}_{4}$ $\cdot \mathrm{H}_{2} \mathrm{O}$ nanosheet provides an environmentally friendly and sustainable way toward conversion of FA to furfuraldehyde [69]. Monolayer $\mathrm{H}_{1.4} \mathrm{Ti}_{1.65} \mathrm{O}_{4} \cdot \mathrm{H}_{2} \mathrm{O}$ nanosheet is a lepidocrocite-type photocatalyst composed of a polyanion layer, which is constructed from a twisted $\mathrm{TiO}_{6}$ octahedral plate with rich defects. Because of the ultrathin structure of monolayer $\mathrm{H}_{1.4} \mathrm{Ti}_{1.65} \mathrm{O}_{4} \cdot \mathrm{H}_{2} \mathrm{O}$ nanosheet, many unsaturated surface metal sites (USMSs) are fully exposed on the monolayer nanosheet and serve as the Lewis acid sites [70, 71]. Consequently, the FA molecules are activated on $\mathrm{H}_{1.4} \mathrm{Ti}_{1.65} \mathrm{O}_{4} \cdot \mathrm{H}_{2} \mathrm{O}$ nanosheet because of the intimate interaction between USMSs and FA. Hydrogen nuclear magnetic resonance ( $\left.{ }^{1} \mathrm{HNMR}\right)$ spectroscopy and in situ Fourier transform infrared spectroscopy (FTIR) results illustrate that $\mathrm{H}_{1.4} \mathrm{Ti}_{1.65} \mathrm{O}_{4} \cdot \mathrm{H}_{2} \mathrm{O}$ possesses more surface Lewis and Brønsted acid sites than the layered counterpart. Lewis acid sites serve as the active sites for effectively adsorbing and activating FA molecules, and Brønsted acid sites significantly improve photocatalytic performance. Based on the above results, a proposed photocatalytic mechanism for the photocatalytic oxidation of FA to furfuraldehyde over $\mathrm{H}_{1.4} \mathrm{Ti}_{1.65} \mathrm{O}_{4} \cdot \mathrm{H}_{2} \mathrm{O}$ is elucidated in Fig. 10. Under visible light, the surface Lewis acid sites of $\mathrm{H}_{1.4} \mathrm{Ti}_{1.65} \mathrm{O}_{4} \cdot \mathrm{H}_{2} \mathrm{O}$ effectively adsorb and activate FA molecules, and $\mathrm{O}_{2}$ is captured by photogenerated electrons to form $\mathrm{O}_{2}{ }^{-}$. Thereafter, the absorbed $\mathrm{FA}$ on $\mathrm{H}_{1.4} \mathrm{Ti}_{1.65} \mathrm{O}_{4} \cdot \mathrm{H}_{2} \mathrm{O}$ is deprotonated to generate the active $\mathrm{C}_{5} \mathrm{H}_{5} \mathrm{O}_{2}{ }^{+}$intermediate, and this intermediate further releases a proton with the assistance of $\mathrm{O}_{2}{ }^{-}$to produce furfuraldehyde. Because of the weak interactions between $\mathrm{H}_{1.4} \mathrm{Ti}_{1.65} \mathrm{O}_{4} \cdot \mathrm{H}_{2} \mathrm{O}$ and furfuraldehyde, furfuraldehyde can successfully release from the surface of $\mathrm{H}_{1.4} \mathrm{Ti}_{1.65} \mathrm{O}_{4} \cdot \mathrm{H}_{2} \mathrm{O}$, leading to a high furfuraldehyde selectivity.

\section{FA Oxidation Coupled with Photocatalytic $\mathrm{H}_{2}$ Generation}

To effectively use photogenerated electrons and holes, $\mathrm{Ti}_{3} \mathrm{C}_{2} \mathrm{~T}_{x}$ MXene and cadmium sulfide $\left(\mathrm{Ti}_{3} \mathrm{C}_{2} \mathrm{~T}_{x} / \mathrm{CdS}\right)$ are integrated via a low-temperature wet chemistry approach for FA transformation integrated with $\mathrm{H}_{2}$ evolution. In the $\mathrm{Ti}_{3} \mathrm{C}_{2} \mathrm{~T}_{x} / \mathrm{CdS}$ composites, $\mathrm{Ti}_{3} \mathrm{C}_{2} \mathrm{~T}_{x}$ serves as an "electron

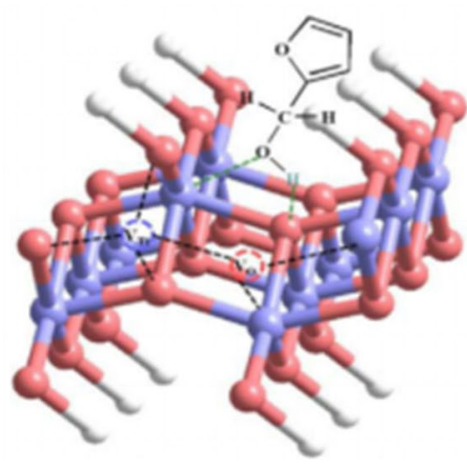

Furfuryl alcohol adsorb on the active sites

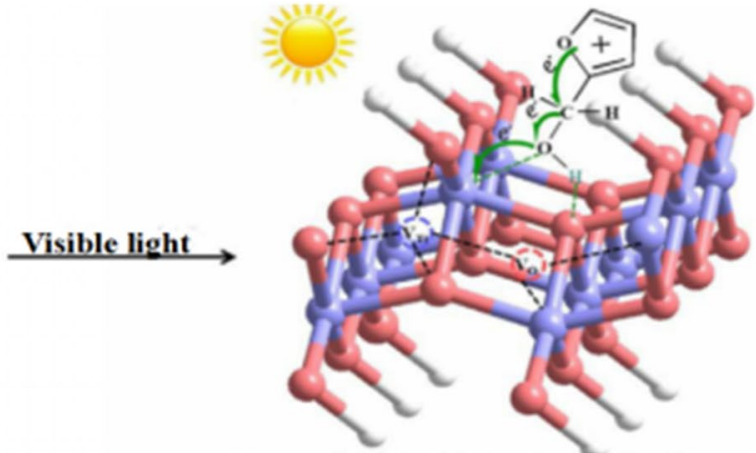

Photo-induced electron stransition from the furfuryl alcohol to the surface $\mathrm{Ti}$ atom

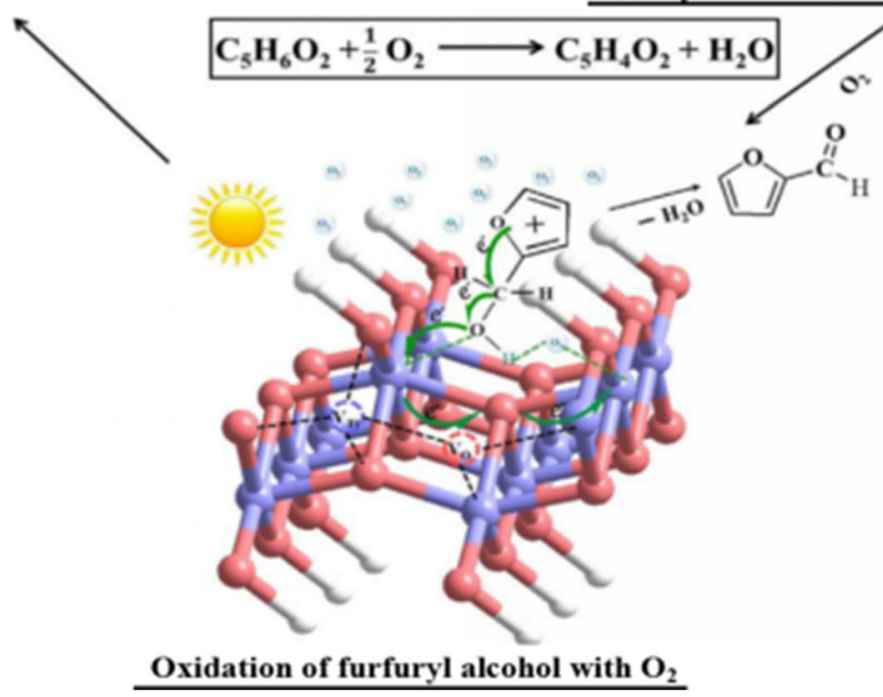

Fig. 10 Proposed reaction mechanism for the photocatalytic selective oxidation of FA over $\mathrm{H}_{1.4} \mathrm{Ti}_{1.65} \mathrm{O}_{4} \cdot \mathrm{H}_{2} \mathrm{O}$ with $\mathrm{O}_{2}$. Reprinted with permission from Ref. [69]. Copyright 2018 Elsevier 
sink" to trap photoexcited electrons from CdS, thereby leading to the moderate photoactivity of FA oxidation coupled with $\mathrm{H}_{2}$ production (Table 1, entry 9) [68]. The possible mechanism shows that the photogenerated charge carriers are initially formed in CdS under visible light irradiation. The electrons easily migrate from the $\mathrm{CB}$ of $\mathrm{CdS}$ to the $\mathrm{Ti}_{3} \mathrm{C}_{2} \mathrm{~T}_{x}$ because of the low Fermi energy level of $\mathrm{Ti}_{3} \mathrm{C}_{2} \mathrm{~T}_{x}$ and the close interfacial connection between $\mathrm{CdS}$ and $\mathrm{Ti}_{3} \mathrm{C}_{2} \mathrm{~T}_{x}[72,73]$, and then the photogenerated electrons react with $\mathrm{H}_{2} \mathrm{O}$ to yield $\mathrm{H}_{2}$. Simultaneously, FA is oxidized into furfural by the photogenerated holes.

\section{Photocatalytic Conversion of Benzyl Alcohol (BA)}

\section{Selective Oxidation of BA}

BA as a biofeedstock model substrate can be converted into not only carbonyl compounds but also $\mathrm{C}-\mathrm{C}$ coupled chemicals by using renewable solar energy, and these compounds are the essential precursors for the synthesis of fragrances, confectioneries and pharmaceuticals [17, 74]. DiMeglio and coworkers [75] have uncovered that nitrate mediators (nitrate salts of manganese, calcium, lithium and magnesium) improve the photocatalytic performance of BA oxidation to benzaldehyde (BAD) over CdS nanowires. To further understand the role of nitrate in this system, tetramethylethylene (TME) as a nitrate radical trap is introduced to the

(a)

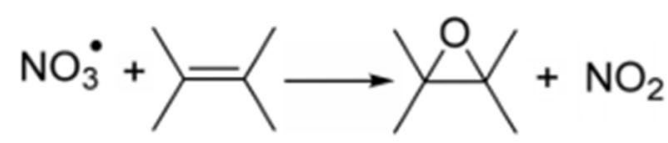

(c)

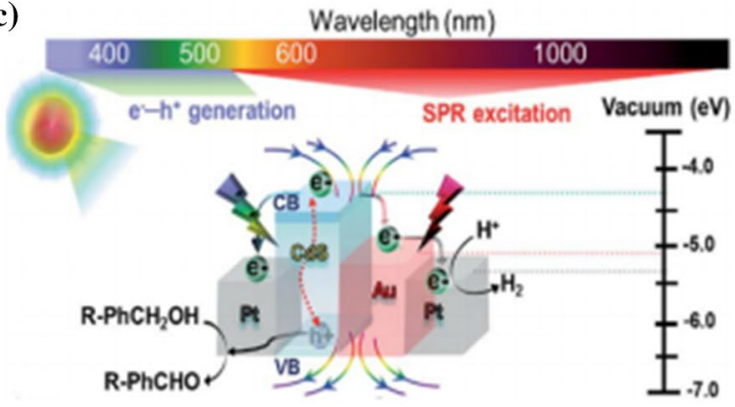

photocatalytic BA oxidation reaction, in which the nitrate radical $\left(\mathrm{NO}_{3}\right)$ and TME undergo an olefin epoxidation to liberate $\mathrm{NO}_{2}$ (Fig. 11a), implying the generation of $\mathrm{NO}_{3}$ Compared with nitrate-free BA solution, a negligible difference in the photocatalytic reaction rate is observed in nitratefree BA solution with TME. However, the photoactivity of BA oxidation is significantly decreased by adding TME to the $\mathrm{LiNO}_{3}$-containing solution, suggesting that $\mathrm{NO}_{3}{ }^{-}$is oxidized to $\mathrm{NO}_{3}$ over $\mathrm{CdS}$, which then mediates $\mathrm{BA}$ conversion into BAD. Kinetic and trapping experiments suggest that selective oxidation of BA to BAD undergoes a mechanism mediated by $\mathrm{NO}_{3}$ radicals instead of being directly oxidized by photoexcited holes. The $\mathrm{O}_{2}{ }^{-}$formed by photogenerated electrons acts as a base, and another $\mathrm{NO}_{3}$ radical mediates the second electron transfer necessary for BAD production (Fig. 11b). In addition, nitrate-mediated unfunctionalized CdS nanowires also oxidize HMF into DFF, while no HMF oxidation is observed in the absence of the nitrate mediator. This study provides new opportunities for facile nitrate salts mediated biomass upgrading.

\section{BA Oxidation Coupled with Photocatalytic $\mathrm{H}_{2}$ Generation}

Coproduction of value-added chemicals and $\mathrm{H}_{2}$ can be obtained from organic feedstocks by making full use of photogenerated holes and electrons. CdS deposited anisotropic Pt-tipped Au nanorods ( $\mathrm{Au}-\mathrm{Pt} @ \mathrm{CdS}$ ), a dual-function (b)

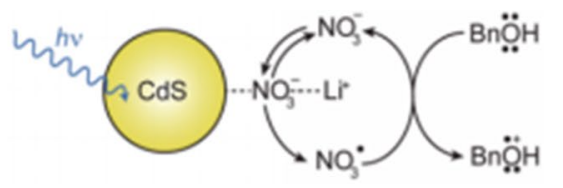

(d)

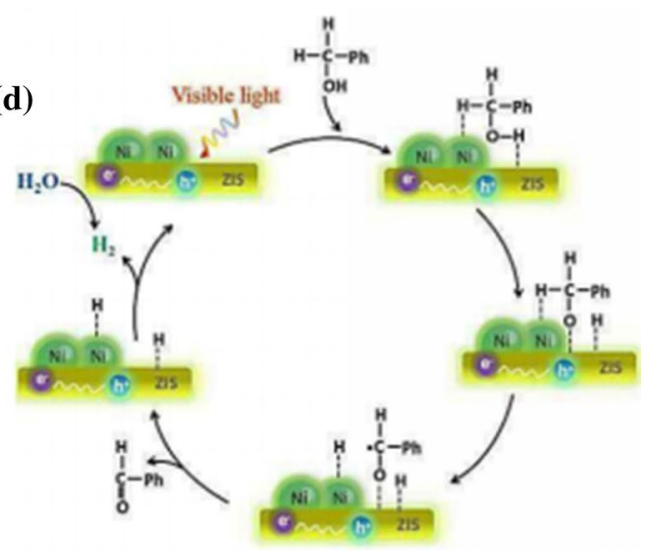

Fig. 11 a Chemical equation of olefin epoxidation between TME and $\mathrm{NO}_{3}$ b Schematic illustration of photocatalytic oxidation of BA mediated by $\mathrm{LiNO}_{3}$. Reprinted with permission from Ref. [75]. Copyright 2019 American Chemical Society. c Schematic diagrams of the energy band lineup and SPR-coupled multichannel electron migration in the ternary $\mathrm{Au}-\mathrm{Pt} @ \mathrm{CdS}$ composite $\left(\mathrm{CB}, \mathrm{VB}, \mathrm{e}^{-}\right.$and $\mathrm{h}^{+}$are the conduction band, valence band, photogenerated electrons and holes, respectively). Reprinted with permission from Ref. [76]. Copyright 2019 The Royal Society of Chemistry. d Probable reaction mechanism for photocatalytic BA transformation integrated with $\mathrm{H}_{2}$ production over $\mathrm{Ni}: \mathrm{Zn}_{2} \mathrm{InS}_{4}\left(\mathrm{e}^{-}\right.$and $\mathrm{h}^{+}$are photogenerated electrons and holes, respectively). Reprinted with permission from Ref. [82]. Copyright 2020 Elsevier 
photocatalyst, is applied to the transformation of BA to $\mathrm{H}_{2}$ and BAD under Vis-NIR light irradiation [76]. The results show that the Au-Pt@CdS composite exhibits higher production of $\mathrm{H}_{2}$ and $\mathrm{BAD}$ than $\mathrm{CdS}$ deposited Au nanorods (Au@ $\mathrm{CdS}$ ) and $\mathrm{CdS}$ deposited Pt-covered Au nanorods (Au@ Pt@CdS), indicating that the spatial distribution of metal components and the composition of bimetal-semiconductor composites affect photocatalytic activity. In the Au@Pt@ CdS composites, the unique surface plasmon resonance (SPR) of Au nanorods not only boosts light absorption but also enhances the local electric field, thus promoting the charge carrier generation and transfer of CdS. Pt nanoparticles anisotropically located at the tips of Au nanorods act as a cocatalyst and an electron reservoir to drive the directional charge transfer and promote the proton reduction. As a result, an excellent activity of coproduction of $\mathrm{BAD}$ and $\mathrm{H}_{2}$ from BA is achieved. Mechanistic studies demonstrate that when the Au-Pt@CdS composite is simulated by Vis-NIR light $(\lambda>420 \mathrm{~nm})$, the CdS is excited by short wavelength visible light $(420 \mathrm{~nm}<\lambda<520 \mathrm{~nm})$ to yield charge carriers. Moreover, the SPR excitation of plasmonic Au-Pt bimetal by longer wavelength light offers an enhanced electric field to improve the photoabsorption, and facilitates the charge carriers generation and separation in CdS [77-79]. Afterward, the photogenerated electrons migrate from the $\mathrm{CB}$ of $\mathrm{CdS}$ to the anisotropic $\mathrm{Au}-\mathrm{Pt}$ bimetal component, and then the electrons combine with protons to generate $\mathrm{H}_{2}$ by diffusing through the porous and loose CdS thin layer [80, 81]. BA is selectively oxidized into BAD through the holes accumulated in the VB of CdS (Fig. 11c). The photogenerated charge carriers in ternary Au-Pt@CdS are spatially separated, and their recombination is remarkably inhibited, which leads to enhanced photocatalytic performance.

Recently, our group synthesized a flower-like nickel modified $\mathrm{ZnIn}_{2} \mathrm{~S}_{4}\left(\mathrm{Ni}: \mathrm{ZnIn}_{2} \mathrm{~S}_{4}\right)$ composite via a photodeposition method to tune the selectivity of BA oxidation [82]. Compared to blank $\mathrm{ZnIn}_{2} \mathrm{~S}_{4}, \mathrm{Ni}: \mathrm{ZnIn}_{2} \mathrm{~S}_{4}$ exhibits a higher BAD selectivity, because the $\mathrm{Ni}$ site facilitates the $\alpha$-H abstraction to inhibit the formation of hydrobenzoin (HB). In addition, control experiments and the EPR technique jointly confirm that the $\mathrm{CH}(\mathrm{OH}) \mathrm{Ph}$ free radicals are the main active species in the reaction. Similarly, Ni-based compound $\left(\mathrm{Ni}_{x} \mathrm{P}\right.$ and $\mathrm{NiS}$ ) modified $\mathrm{ZnIn}_{2} \mathrm{~S}_{4}$ composites are also favorable to $\alpha-\mathrm{H}$ abstraction, showing a photoactivity and selectivity trend analogous to that of $\mathrm{Ni}: \mathrm{ZnIn}_{2} \mathrm{~S}_{4}$. A possible mechanism for photocatalytic transformation of BA integrated with $\mathrm{H}_{2}$ production over Ni:ZnIn $\mathrm{S}_{4}$ is sketched in Fig. 11d. The $\mathrm{ZnIn}_{2} \mathrm{~S}_{4}$ component in the Ni:ZnIn $\mathrm{S}_{4}$ composite is initially excited to generate charge carriers under visible light. The electrons flow from the $\mathrm{CB}$ of $\mathrm{ZnIn}_{2} \mathrm{~S}_{4}$ to the Ni sites, and then protons originating from water combine with the photogenerated electrons to yield $\mathrm{H}_{2}$. Simultaneously, the proton of $\mathrm{OH}$ group in BA is adsorbed on the surface of $\mathrm{ZnIn}_{2} \mathrm{~S}_{4}$ and the other proton abstracted from $\mathrm{C}-\mathrm{H}$ is adsorbed by the Ni site, forming two abstracted protons and a $\mathrm{CH}(\mathrm{OH}) \mathrm{Ph}$ radical. Finally, BAD is formed from the $\mathrm{CH}(\mathrm{OH}) \mathrm{Ph}$ radical oxidation by holes, and abstracted protons are either reduced by photogenerated electrons to release $\mathrm{H}_{2}$ or adsorbed on $\mathrm{Ni}: \mathrm{ZnIn}_{2} \mathrm{~S}_{4}$. This work offers a paradigm for tuning the selectivity of target-oriented biomass intermediates valorization to obtain fuels and high-value-added chemicals.

\section{Tunable Flexibility of Target Products from BA}

Interestingly, the different product distributions of BA oxidation can be tuned by photodepositing the low-valent $\mathrm{Cd}$ atoms onto the surface of the CdS quantum dots (QDs) modified with mercaptopropionate ligands. Weiss's group [16] has achieved a high selectivity of $\mathrm{C}-\mathrm{C}$ coupling products (mainly hydrobenzoin) with the addition of $\mathrm{Cd}\left(\mathrm{ClO}_{4}\right)_{2}$ to the reaction to promote $\mathrm{Cd}^{0}$ photodeposition. However, a high BAD selectivity (99\%) is obtained by adding an electron scavenger (anthroquinone-2-sulfonate) to the same reaction to inhibit the photodeposition of $\mathrm{Cd}^{0}$. Furthermore, the selectivity of $\mathrm{C}-\mathrm{C}$ coupled products reaches $91 \%(68 \%$ hydrobenzoin, $15 \%$ benzil, and $8 \%$ 2-phenyl-acetophenone) by increasing the concentration of BA from $2 \mathrm{mmol} / \mathrm{L}$ to $5 \mathrm{mmol} / \mathrm{L}$, because a higher $\alpha$-hydroxybenzyl radical favors $\mathrm{C}-\mathrm{C}$ coupling. On the contrary, the introduction of an electron scavenger not only effectively inhibits $\mathrm{C}-\mathrm{C}$ coupling by preventing deposition of $\mathrm{Cd}^{0}$ (Fig. 12a) but also removes the coulombic attraction of the hole in the CdS QDs, thereby the $\alpha$-hydroxybenzyl radical intermediate can transfer to a photoexcited hole before coupling occurs.

In another example, Wang's group [17] achieved controllable benzoin (BZ) or deoxybenzoin (DOB) production from BA accompanied by $\mathrm{H}_{2}$ evolution over $\mathrm{Zn}_{x} \mathrm{In}_{2} \mathrm{~S}_{3+x}$. The variation between $\mathrm{DOB}$ and $\mathrm{BZ}$ is related to the bottom potential of the CB of $\mathrm{Zn}_{x} \mathrm{In}_{2} \mathrm{~S}_{3+x}$, which can be manipulated by changing the relative contents of the indium and zinc precursors. In the ternary $\mathrm{Zn}_{x} \mathrm{In}_{2} \mathrm{~S}_{3+x}$, a higher $\mathrm{Zn} / \mathrm{In}$ ratio corresponds to a lower CB bottom potential of the $\mathrm{Zn}_{x} \mathrm{In}_{2} \mathrm{~S}_{3+x}$ [83], leading to a high reduction capacity and contributing to the production of DOB. To understand the reaction pathway, the time distribution curve of the photocatalytic transformation of BA over $\mathrm{Zn}_{0.6} \mathrm{In}_{2} \mathrm{~S}_{3.6}$ was investigated. As depicted in Fig. $12 \mathrm{~b}$, BA is rapidly converted into $\mathrm{HB}$ and $\mathrm{H}_{2}$ using blue LED illumination, and a maximum yield (62\%) of HB appears after $4 \mathrm{~h}$ of irradiation. Afterward, the amounts of dominant product $\mathrm{DOB}$, by-products $\mathrm{BZ}$ and trimers increase with decreasing $\mathrm{HB}$, accompanied by the production of $\mathrm{H}_{2}$. Additionally, control experiments were conducted to prove that $\mathrm{HB}$ is the intermediate in the production of DOB and BZ. As sketched in Fig. $12 \mathrm{c}, \mathrm{Zn}_{0.6} \mathrm{In}_{2} \mathrm{~S}_{3.6}$ displays a moderate DOB yield (64\%) and a relatively low yield of BZ (22\%) under the illumination of blue LED. In comparison, the reaction over $\mathrm{Zn}_{0.2} \mathrm{In}_{2} \mathrm{~S}_{3.2}$ 

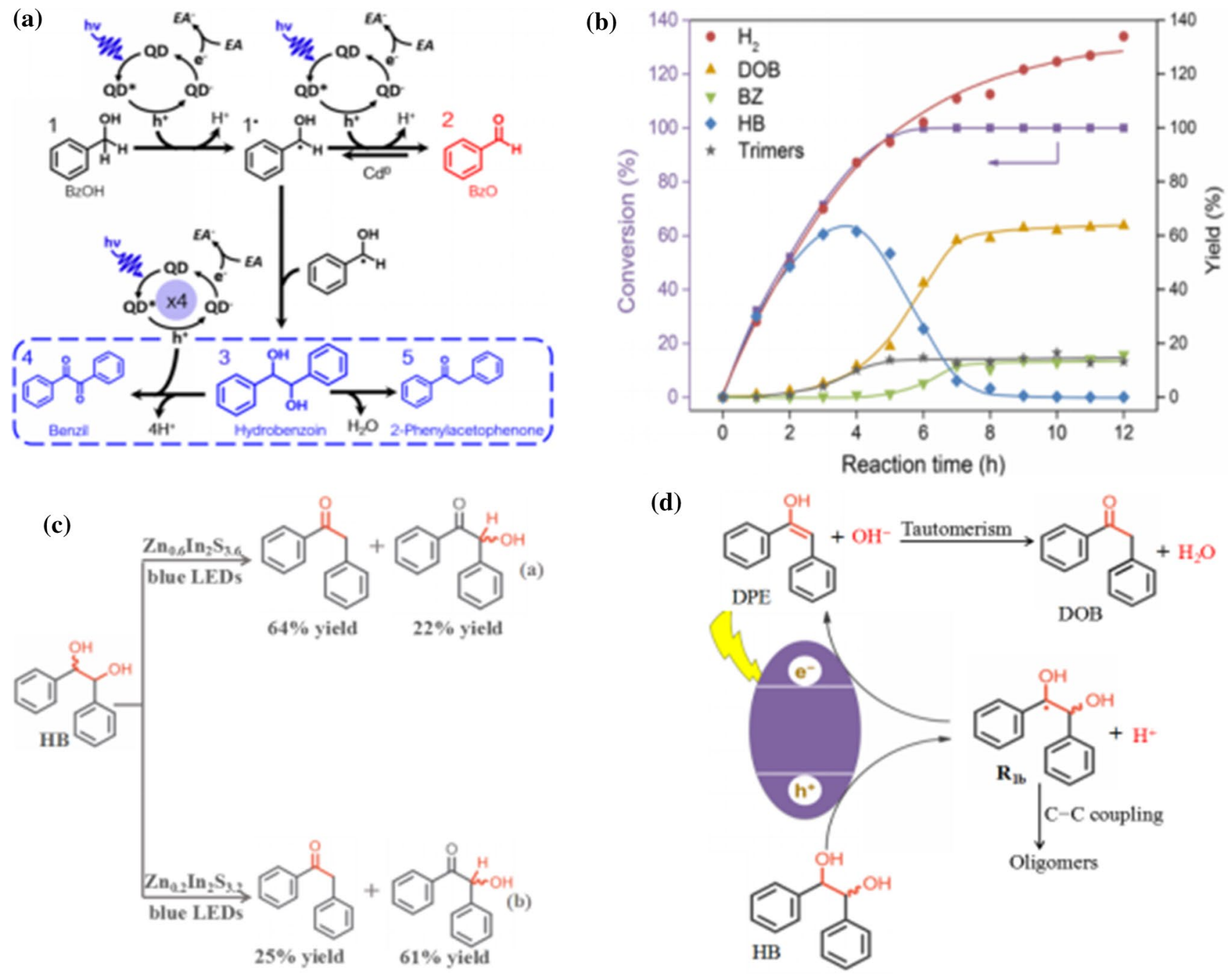

(d)

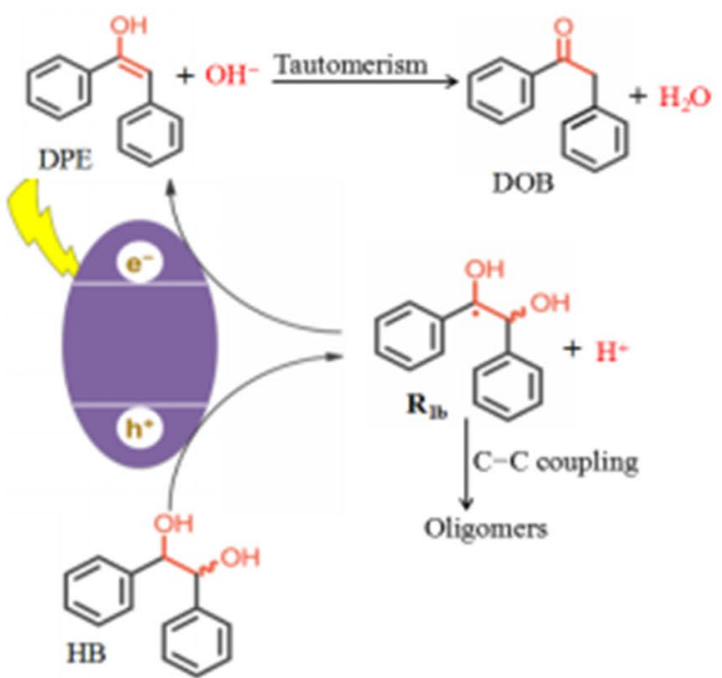

Fig. 12 a Schematic diagram of the mechanism for photooxidation of BA. Reprinted with permission from Ref. [16]. Copyright 2018 American Chemical Society. b Time profile of photocatalytic dehydrocoupling of BA over $\mathrm{Zn}_{0.6} \mathrm{In}_{2} \mathrm{~S}_{3.6}$. c Control experiments for $\mathrm{HB}$

affords BZ and DOB in $61 \%$ and $25 \%$ yield, respectively. The above results further confirm that the variation of target product over the $\mathrm{Zn}_{x} \mathrm{In}_{2} \mathrm{~S}_{3+x}$ can be tuned by altering $\mathrm{Zn} / \mathrm{In}$ ratios. Based on the above analysis, a tentative reaction mechanism of photocatalytic fragmentation of $\mathrm{HB}$ into DOB is proposed in Fig. 12d. Under blue LED irradiation, the cleavage of the $\mathrm{C}-\mathrm{H}$ bond in $\mathrm{HB}$ occurs by photogenerated holes to deliver the $\mathrm{R}_{1 \mathrm{~b}}$ radical. Afterward, the $\mathrm{R}_{1 \mathrm{~b}}$ radical transfers to the $\mathrm{CB}$ and reduces into 1,2-diphenylethenol (DPE) through photogenerated electrons. Finally, DPE tautomerizes to DOB.

conversion over $\mathrm{Zn}_{0.6} \mathrm{In}_{2} \mathrm{~S}_{3.6}$ or $\mathrm{Zn}_{0.2} \mathrm{In}_{2} \mathrm{~S}_{3.2}$. d Possible mechanism for photocatalytic fragmentation of HB into DOB. Reprinted with permission from Ref. [17]. Copyright 2020 American Chemical Society

\section{Conclusions and Outlook}

In summary, we have concisely recapped the recent progress in the photocatalytic upgrading of biomass-derived chemicals, including photocatalytic fragmentation of lignin models and photoredox-catalyzed biomass-relevant alcohols conversion. In particular, we offer the latest overview of visible-light-promoted rupture of $\beta$-O-4 bonds or $\mathrm{C}-\mathrm{C}$ bonds of lignin models into valuable aromatic fragments. Then, we highlight the dual-function photoredox system for $\mathrm{H}_{2}$ production integrated with alcohols oxidation and the photocatalyzed reaction toward controllable target-oriented product variation from the same substrates. Although considerable progress has been made in biomass-derived platform molecules conversion, it cannot meet the current requirements of industrial production, 
and the selectivity of single $\mathrm{C}-\mathrm{C}$ coupling chemicals remains unsatisfactory. Therefore, there remains a wide scope for improving the value of biomass-derived feedstocks for practical applications. In the end, we provide personal insights to further expand the manufacture of biomass-derived compounds molecule valorization under visible light.

First, the efficient strategies for developing and using the complicated and recalcitrant native lignin must be further explored. The viable catalytic tandem reaction systems, by effectively combining photocatalysis and traditional catalysis (thermocatalysis and enzyme catalysis), are anticipated to provide a more efficient and entire use of native lignin. Second, selectivity is a key issue for biomass-relevant derivatives conversion. In this regard, multifunctional semiconductor-based catalysts for tuning the selectivity of the target product are worthy of exploration. For example, surface modification can be used to alter a catalysts' ability to adsorb or desorb intermediates, thereby tuning the selectivity of the target product. In addition, adjusting the band gap of photocatalysts can tailor the suitable oxidation capacity of photogenerated holes for alcohol conversion and different product distributions. Third, photocatalytic dualfunction systems based on simultaneously using photoexcited electrons and holes need to be further established. For instance, assembling biomass-derived platform molecules (e.g., alcohols) oxidation and other reduction reactions, such as $\mathrm{CO}_{2}$ reduction and $\mathrm{N}_{2}$ fixation, offer a promising way to extend cooperative photoredox catalysis to synthesize the value-added chemicals and clean fuels together. Finally, the underlying mechanism of various photocatalytic biomassderived chemical conversions remains to be investigated. In this context, in situ characterization techniques, such as in situ Fourier transform infrared spectroscopy (FTIR) and in situ electron spin resonance (ESR) spectroscopy, in combination with mass spectrometry and theoretical calculations, can be used to track the intermediate species during photocatalysis, which aids the understanding of the specific mechanistic pathway and explains the selectivity of products. It is hoped that this timely overview of the latest advances in photocatalytic biomass-derived compounds upgrading will inspire the rational design of photocatalysts toward selective organic transformations with tunable targetoriented product distributions.

Acknowledgements This work was supported by the National Natural Science Foundation of China (Nos. 21872029, 20903023, U1463204 and 21173045), the Program for Leading Talents of Fujian Universities, the Natural Science Foundation of Fujian Province for the Distinguished Young Investigator Rolling Grant (No. 2017J07002), the 1st Program of Fujian Province for Top Creative Young Talents, the Natural Science Foundation of Fujian Province (No. 2019J0106), and the Award Program for Minjiang Scholar Professorship is gratefully acknowledged.
Open Access This article is licensed under a Creative Commons Attribution 4.0 International License, which permits use, sharing, adaptation, distribution and reproduction in any medium or format, as long as you give appropriate credit to the original author(s) and the source, provide a link to the Creative Commons licence, and indicate if changes were made. The images or other third party material in this article are included in the article's Creative Commons licence, unless indicated otherwise in a credit line to the material. If material is not included in the article's Creative Commons licence and your intended use is not permitted by statutory regulation or exceeds the permitted use, you will need to obtain permission directly from the copyright holder. To view a copy of this licence, visit http://creativecommons.org/licenses/by/4.0/.

\section{References}

1. Goldemberg J (2007) Ethanol for a sustainable energy future. Science 315(5813):808-810

2. Tuck CO, Perez E, Horvath IT et al (2012) Valorization of biomass: deriving more value from waste. Science 337(6095):695-699

3. Gilkey MJ, Xu BJ (2016) Heterogeneous catalytic transfer hydrogenation as an effective pathway in biomass upgrading. ACS Catal 6(3):1420-1436

4. Rai M, Ingle AP, Pandit R et al (2019) Emerging role of nanobiocatalysts in hydrolysis of lignocellulosic biomass leading to sustainable bioethanol production. Catal Rev 61(1):1-26

5. Zaheer M, Kempe R (2015) Catalytic hydrogenolysis of aryl ethers: a key step in lignin valorization to valuable chemicals. ACS Catal 5(3):1675-1684

6. Zhang J (2018) Conversion of lignin models by photoredox catalysis. Chemsuschem 11(18):3071-3080

7. Li SH, Liu SQ, Colmenares JC et al (2016) A sustainable approach for lignin valorization by heterogeneous photocatalysis. Green Chem 18(3):594-607

8. Li CZ, Zhao XC, Wang AQ et al (2015) Catalytic transformation of lignin for the production of chemicals and fuels. Chem Rev 115(21):11559-11624

9. Gallezot P (2012) Conversion of biomass to selected chemical products. Chem Soc Rev 41(4):1538-1558

10. Krivtsov I, García-López EI, Marcì G et al (2017) Selective photocatalytic oxidation of 5-hydroxymethyl-2-furfural to 2,5-furandicarboxyaldehyde in aqueous suspension of $\mathrm{g}-\mathrm{C}_{3} \mathrm{~N}_{4}$. Appl Catal B 204:430-439

11. Wang Q, Hou W, Li S et al (2017) Hydrophilic mesoporous poly(ionic liquid)-supported $\mathrm{Au}-\mathrm{Pd}$ alloy nanoparticles towards aerobic oxidation of 5-hydroxymethylfurfural to 2,5-furandicarboxylic acid under mild conditions. Green Chem 19(16):3820-3830

12. Chai ZG, Zeng TT, Li Q et al (2016) Efficient visible light-driven splitting of alcohols into hydrogen and corresponding carbonyl compounds over a Ni-modified CdS photocatalyst. J Am Chem Soc 138(32):10128-10131

13. Han GQ, Jin YH, Burgess RA et al (2017) Visible-light-driven valorization of biomass intermediates integrated with $\mathrm{H}_{2}$ production catalyzed by ultrathin Ni/CdS nanosheets. J Am Chem Soc 139(44):15584-15587

14. Jiang DC, Chen X, Zhang Z et al (2018) Highly efficient simultaneous hydrogen evolution and benzaldehyde production using cadmium sulfide nanorods decorated with small cobalt nanoparticles under visible light. J Catal 357:147-153

15. Xu Y, Zeng LZ, Fu ZC et al (2018) Photocatalytic oxidation of arylalcohols to aromatic aldehydes promoted by hydroxyl radicals over a CoP/CdS photocatalyst in water with hydrogen evolution. Catal Sci Technol 8(10):2540-2545

16. McClelland KP, Weiss EA (2019) Selective photocatalytic oxidation of benzyl alcohol to benzaldehyde or $\mathrm{C}-\mathrm{C}$ coupled 
products by visible-light-absorbing quantum dots. ACS Appl Energy Mater 2(1):92-96

17. Luo NC, Hou TT, Liu SY et al (2020) Photocatalytic coproduction of deoxybenzoin and $\mathrm{H}_{2}$ through tandem redox reactions. ACS Catal 10(1):762-769

18. Zhang CF, Lu JM, Zhang XC et al (2016) Cleavage of the lignin $\beta-\mathrm{O}-4$ ether bond via a dehydroxylation-hydrogenation strategy over a NiMo sulfide catalyst. Green Chem 18(24):6545-6555

19. Chakar FS, Ragauskas AJ (2004) Review of current and future softwood kraft lignin process chemistry. Ind Crops Prod 20(2):131-141

20. Yue FX, Lu FC, Sun RC et al (2012) Synthesis and characterization of new 5-linked pinoresinol lignin models. Chem Eur J 18(51):16402-16410

21. Parthasarathi R, Romero RA, Redondo A et al (2011) Theoretical study of the remarkably diverse linkages in lignin. J Phys Chem Lett 2(20):2660-2666

22. Wang YL, Liu Y, He JH et al (2019) Redox-neutral photocatalytic strategy for selective $\mathrm{C}-\mathrm{C}$ bond cleavage of lignin and lignin models via PCET process. Sci Bull 64(22):1658-1666

23. Chen J, Cen J, Xu XL et al (2016) The application of heterogeneous visible light photocatalysts in organic synthesis. Catal Sci Technol 6(2):349-362

24. Li JY, Li YH, Qi MY et al (2020) Selective organic transformations over cadmium sulfide-based photocatalysts. ACS Catal 10(11):6262-6280

25. Weng B, Quan XuYJ (2016) Decorating geometry- and sizecontrolled sub-20 nm Pd nanocubes onto $2 \mathrm{D} \mathrm{TiO}_{2}$ nanosheets for simultaneous $\mathrm{H}_{2}$ evolution and 1,1-diethoxyethane production. J Mater Chem A 4(47):18366-18377

26. Li JY, Li YH, Zhang F et al (2020) Visible-light-driven integrated organic synthesis and hydrogen evolution over 1D/2D CdS- $\mathrm{Ti}_{3} \mathrm{C}_{2} \mathrm{~T}_{x}$ MXene composites. Appl Catal B Environ 269:118783

27. Lin XY, Li YH, Qi MY et al (2020) A unique coordination-driven route for the precise nanoassembly of metal sulfides on metalorganic frameworks. Nanoscale Horiz 5(4):714-719

28. Xie XQ, Zhang N, Tang ZR et al (2018) $\mathrm{Ti}_{3} \mathrm{C}_{2} \mathrm{~T}_{x}$ MXene as a Janus cocatalyst for concurrent promoted photoactivity and inhibited photocorrosion. Appl Catal B Environ 237:43-49

29. Cao Y, Wang N, He X et al (2018) Photocatalytic oxidation and subsequent hydrogenolysis of lignin $\beta$-O-4 models to aromatics promoted by in situ carbonic acid. ACS Sustain Chem Eng 6(11):15032-15039

30. Luo NC, Wang M, Li HJ et al (2016) Photocatalytic oxidationhydrogenolysis of lignin $\beta$-O-4 models via a dual light wavelength switching strategy. ACS Catal 6(11):7716-7721

31. Luo NC, Wang M, Li HJ et al (2017) Visible-light-driven selfhydrogen transfer hydrogenolysis of lignin models and extracts into phenolic products. ACS Catal 7(7):4571-4580

32. Wu XJ, Fan XT, Xie SJ et al (2018) Solar energy-driven ligninfirst approach to full utilization of lignocellulosic biomass under mild conditions. Nat Catal 1(10):772-780

33. Zoia L, Argyropoulos DS (2009) Detection of ketyl radicals using ${ }^{31}$ P NMR spin trapping. J Phys Org Chem 23(6):505-512

34. Argyropoulos DS, Li HY, Gaspar AR et al (2006) Quantitative ${ }^{31} \mathrm{P}$ NMR detection of oxygen-centered and carbon-centered radical species. Bioorg Med Chem 14(12):4017-4028

35. Cho SH, Kim JY, Kwak J et al (2011) Recent advances in the transition metal-catalyzed twofold oxidative $\mathrm{C}-\mathrm{H}$ bond activation strategy for $\mathrm{C}-\mathrm{C}$ and $\mathrm{C}-\mathrm{N}$ bond formation. Chem Soc Rev 40(10):5068-5083

36. Hou TT, Luo NC, Li HJ et al (2017) Yin and Yang dual characters of $\mathrm{CuOx}$ clusters for $\mathrm{C}-\mathrm{C}$ bond oxidation driven by visible light. ACS Catal 7(6):3850-3859. https://doi.org/10.1021/acsca tal.7b00629
37. Senanayake SD, Stacchiola D, Rodriguez JA (2013) Unique properties of ceria nanoparticles supported on metals: novel inverse ceria/copper catalysts for $\mathrm{CO}$ oxidation and the water-gas shift reaction. Acc Chem Res 46(8):1702-1711

38. Lee Y, He GH, Akey AJ et al (2011) Raman analysis of mode softening in nanoparticle $\mathrm{CeO}_{(2-\delta)}$ and $\mathrm{Au}-\mathrm{CeO}_{(2-\delta)}$ during $\mathrm{CO}$ oxidation. J Am Chem Soc 133(33):12952-12955

39. Wu ZL, Li MJ, Howe J et al (2010) Probing defect sites on $\mathrm{CeO}_{2}$ nanocrystals with well-defined surface planes by Raman spectroscopy and $\mathrm{O}_{2}$ adsorption. Langmuir 26(21):16595-16606

40. Deori K, Gupta D, Saha B et al (2014) Design of 3-dimensionally self-assembled $\mathrm{CeO}_{2}$ nanocube as a breakthrough catalyst for efficient alkylarene oxidation in water. ACS Catal 4(9):3169-3179

41. Gazi S, Hung Ng WK, Ganguly R et al (2015) Selective photocatalytic $\mathrm{C}-\mathrm{C}$ bond cleavage under ambient conditions with earth abundant vanadium complexes. Chem Sci 6(12):7130-7142

42. Liu HF, Li HJ, Lu JM et al (2018) Photocatalytic cleavage of $\mathrm{C}-\mathrm{C}$ bond in lignin models under visible light on mesoporous graphitic carbon nitride through $\pi-\pi$ stacking interaction. ACS Catal 8(6):4761-4771

43. Lan HC, Li LL, An XQ et al (2017) Microstructure of carbon nitride affecting synergetic photocatalytic activity: hydrogen bonds vs. structural defects. Appl Catal B 204:49-57

44. Liu F, Feng ND, Wang Q et al (2017) Transfer channel of photoinduced holes on $\mathrm{a} \mathrm{TiO}_{2}$ surface as revealed by solid-state nuclear magnetic resonance and electron spin resonance spectroscopy. $\mathbf{J}$ Am Chem Soc 139(29):10020-10028

45. Ji JJ, Wen J, Shen YF et al (2017) Simultaneous noncovalent modification and exfoliation of 2D carbon nitride for enhanced electrochemiluminescent biosensing. J Am Chem Soc 139(34):11698-11701

46. Goettmann F, Fischer A, Antonietti M et al (2006) Chemical synthesis of mesoporous carbon nitrides using hard templates and their use as a metal-free catalyst for Friedel-Crafts reaction of benzene. Angew Chem Int Ed 45(27):4467-4471

47. Mitchell LJ, Moody CJ (2014) Solar photochemical oxidation of alcohols using catalytic hydroquinone and copper nanoparticles under oxygen: oxidative cleavage of lignin models. J Org Chem 79(22):11091-11100

48. Liu XQ, Duan XG, Wei W et al (2019) Photocatalytic conversion of lignocellulosic biomass to valuable products. Green Chem 21(16):4266-4289

49. Butburee T, Chakthranont P, Phawa C et al (2020) Beyond artificial photosynthesis: prospects on photobiorefinery. ChemCatChem 12(7):1873-1890

50. Marcì G, García-López EI, Pomilla FR et al (2019) Photoelectrochemical and EPR features of polymeric $\mathrm{C}_{3} \mathrm{~N}_{4}$ and O-modified $\mathrm{C}_{3} \mathrm{~N}_{4}$ employed for selective photocatalytic oxidation of alcohols to aldehydes. Catal Today 328:21-28

51. Zhang YH, Zhang N, Tang ZR et al (2013) Identification of $\mathrm{Bi}_{2} \mathrm{WO}_{6}$ as a highly selective visible-light photocatalyst toward oxidation of glycerol to dihydroxyacetone in water. Chem Sci 4(4):1820-1824

52. Hu L, Xu JX, Zhou SY et al (2018) Catalytic advances in the production and application of biomass-derived 2,5-dihydroxymethylfuran. ACS Catal 8(4):2959-2980

53. Xu S, Zhou P, Zhang ZH et al (2017) Selective oxidation of 5-hydroxymethylfurfural to 2,5-furandicarboxylic acid using $\mathrm{O}_{2}$ and a photocatalyst of Co-thioporphyrazine bonded to $\mathrm{g}-\mathrm{C}_{3} \mathrm{~N}_{4}$. J Am Chem Soc 139(41):14775-14782

54. Zheng YZ, Zhang DK, Shah SNA et al (2017) Ultra-weak chemiluminescence enhanced by facilely synthesized nitrogen-rich quantum dots through chemiluminescence resonance energy transfer and electron hole injection. Chem Commun 53(41):5657-5660

55. Chen YZ, Wang ZU, Wang HW et al (2017) Singlet oxygen-engaged selective photo-oxidation over Pt nanocrystals/ 
porphyrinic MOF: the roles of photothermal effect and Pt electronic state. J Am Chem Soc 139(5):2035-2044

56. Galkin KI, Krivodaeva EA, Romashov LV et al (2016) Critical influence of 5-hydroxymethylfurfural aging and decomposition on the utility of biomass conversion in organic synthesis. Angew Chem Int Ed 55(29):8338-8342

57. Ma B, Wang YY, Guo XN et al (2018) Photocatalytic synthesis of 2,5-diformylfuran from 5-hydroxymethyfurfural or fructose over bimetallic $\mathrm{Au}-\mathrm{Ru}$ nanoparticles supported on reduced graphene oxides. Appl Catal A Gen 552:70-76

58. Zhang HL, Wu Q, Guo C et al (2017) Photocatalytic selective oxidation of 5-hydroxymethylfurfural to 2,5-diformylfuran over $\mathrm{Nb}_{2} \mathrm{O}_{5}$ under visible light. ACS Sustain Chem Eng $5(4): 3517-3523$

59. Meng SG, Wu HH, Cui YJ et al (2020) One-step synthesis of 2D/2D-3D NiS/ $/ \mathrm{Zn}_{3} \mathrm{In}_{2} \mathrm{~S}_{6}$ hierarchical structure toward solar-tochemical energy transformation of biomass-relevant alcohols. Appl Catal B Environ 266:118617

60. Meng SG, Ye XJ, Zhang JH et al (2018) Effective use of photogenerated electrons and holes in a system: photocatalytic selective oxidation of aromatic alcohols to aldehydes and hydrogen production. J Catal 367:159-170

61. Wang XW, Batter B, Xie Y et al (2015) Highly crystalline, small sized, monodisperse $\alpha$-NiS nanocrystal ink as an efficient counter electrode for dye-sensitized solar cells. J Mater Chem A 3(31):15905-15912

62. Battula VR, Jaryal A, Kailasam K (2019) Visible light-driven simultaneous $\mathrm{H}_{2}$ production by water splitting coupled with selective oxidation of HMF to DFF catalyzed by porous carbon nitride. J Mater Chem A 7(10):5643-5649

63. Chen JY, Ge Y, Guo YY et al (2018) Selective hydrogenation of biomass-derived 5-hydroxymethylfurfural using palladium catalyst supported on mesoporous graphitic carbon nitride. J Energy Chem 27(1):283-289

64. Guo YY, Chen JZ (2016) Photo-induced reduction of biomassderived 5-hydroxymethylfurfural using graphitic carbon nitride supported metal catalysts. RSC Adv 6(104):101968-101973

65. Maeda K, Teramura K, Lu DL et al (2006) Photocatalyst releasing hydrogen from water. Nature 440(7082):295

66. Liu MY, You WS, Lei ZB et al (2005) Water reduction and oxidation on $\mathrm{Pt}-\mathrm{Ru} / \mathrm{Y}_{2} \mathrm{Ta}_{2} \mathrm{O}_{5} \mathrm{~N}_{2}$ catalyst under visible light irradiation. Chem Commun 36(2):2192-2193

67. Dong SH, Liu Z, Liu RH et al (2018) Visible-light-induced catalytic transfer hydrogenation of aromatic aldehydes by palladium immobilized on amine-functionalized iron-based metal-organic frameworks. ACS Appl Nano Mater 1(8):4247-4257

68. Li YH, Zhang F, Chen Y et al (2020) Photoredox-catalyzed biomass intermediate conversion integrated with $\mathrm{H}_{2}$ production over $\mathrm{Ti}_{3} \mathrm{C}_{2} \mathrm{~T} / \mathrm{CdS}$ composites. Green Chem 22(1):163-169

69. Wang H, Song YJ, Xiong JH et al (2018) Highly selective oxidation of furfuryl alcohol over monolayer titanate nanosheet under visible light irradiation. Appl Catal B Environ 224:394-403

70. Xie JF, Li S, Zhang XD et al (2014) Atomically-thin molybdenum nitride nanosheets with exposed active surface sites for efficient hydrogen evolution. Chem Sci 5(12):4615-4620

71. Kitano M, Wada E, Nakajima K et al (2013) Protonated titanate nanotubes with Lewis and Brønsted acidity: relationship between nanotube structure and catalytic activity. Chem Mater 25(3):385-393

72. Chen $Y, X i e X Q$, Xin $X$ et al (2019) $\mathrm{Ti}_{3} \mathrm{C}_{2} \mathrm{~T}_{x}$-based threedimensional hydrogel by a graphene oxide-assisted self-convergence process for enhanced photoredox catalysis. ACS Nano 13(1):295-304

73. Low J, Zhang LY, Tong $\mathrm{T}$ et al (2018) $\mathrm{TiO}_{2} / \mathrm{MXene} \mathrm{Ti}_{3} \mathrm{C}_{2}$ composite with excellent photocatalytic $\mathrm{CO}_{2}$ reduction activity. J Catal 361:255-266
74. Sun YB, Cao CY, Wei F et al (2016) Nanocarbon-based TEMPO as stable heterogeneous catalysts for partial oxidation of alcohols. Sci Bull 61(10):772-777

75. DiMeglio JL, Breuhaus-Alvarez AG, Li SQ et al (2019) Nitratemediated alcohol oxidation on cadmium sulfide photocatalysts. ACS Catal 9(6):5732-5741

76. Han C, Tang ZR, Liu JX et al (2019) Efficient photoredox conversion of alcohol to aldehyde and $\mathrm{H}_{2}$ by heterointerface engineering of bimetal-semiconductor hybrids. Chem Sci 10(12):3514-3522

77. Xu J, Yang WM, Huang SJ et al (2018) CdS core-Au plasmonic satellites nanostructure enhanced photocatalytic hydrogen evolution reaction. Nano Energy 49:363-371

78. Chen JJ, Wu JCS, Wu PC et al (2012) Improved photocatalytic activity of shell-isolated plasmonic photocatalyst $\mathrm{Au} @ \mathrm{SiO}_{2} / \mathrm{TiO}_{2}$ by promoted LSPR. J Phys Chem C 116(50):26535-26542

79. Li CP, Wang P, Tian Y et al (2017) Long-range plasmon field and plasmoelectric effect on catalysis revealed by shell-thicknesstunable pinhole-free $\mathrm{Au} @ \mathrm{SiO}_{2}$ core-shell nanoparticles: a case study of p-nitrophenol reduction. ACS Catal 7(8):5391-5398

80. Ma L, Liang S, Liu XL et al (2015) Synthesis of dumbbell-like gold-metal sulfide core-shell nanorods with largely enhanced transverse plasmon resonance in visible region and efficiently improved photocatalytic activity. Adv Funct Mater 25(6):898-904

81. Ma X, Zhao K, Tang HJ et al (2014) New insight into the role of gold nanoparticles in $\mathrm{Au} @ \mathrm{CdS}$ core-shell nanostructures for hydrogen evolution. Small 10(22):4664-4670

82. Lin Q, Li YH, Qi MY et al (2020) Photoredox dual reaction for selective alcohol oxidation and hydrogen evolution over nickel surface-modified $\mathrm{ZnIn}_{2} \mathrm{~S}_{4}$. Appl Catal B Environ 271:118946

83. Shen SH, Zhao L, Guo LJ (2010) $\mathrm{Zn}_{m} \operatorname{In}_{2} \mathrm{~S}_{3+m}$ ( $m=1-5$, integer): a new series of visible-light-driven photocatalysts for splitting water to hydrogen. Int J Hydrogen Energy 35(19):10148-10154

84. Ye HF, Shi R, Yang X et al (2018) P-doped $\mathrm{Zn}_{x} \mathrm{Cd}_{1-x} \mathrm{~S}$ solid solutions as photocatalysts for hydrogen evolution from water splitting coupled with photocatalytic oxidation of 5-hydroxymethylfurfural. Appl Catal B Environ 233:70-79

85. Hao HC, Zhang L, Wang WZ et al (2019) Photocatalytic hydrogen evolution coupled with efficient selective benzaldehyde production from benzyl alcohol aqueous solution over $\mathrm{ZnS}_{-} \mathrm{Ni}_{x} \mathrm{~S}_{y} \mathrm{com}-$ posites. ACS Sustain Chem Eng 7(12):10501-10508

86. Li JY, Xin Li YH et al (2019) Visible light-induced conversion of biomass-derived chemicals integrated with hydrogen evolution over $2 \mathrm{D} \mathrm{Ni} \mathrm{N}_{2} \mathrm{P}$-graphene- $\mathrm{TiO}_{2}$. Res Chem Intermed 45(12):5935-5946

87. Zhang B, Zhao TJ, Wang HH (2019) Enhanced photocatalytic activity of aerogel composed of crooked carbon nitride nanolayers with nitrogen vacancies. ACS Appl Mater Interfaces 11(38):34922-34929

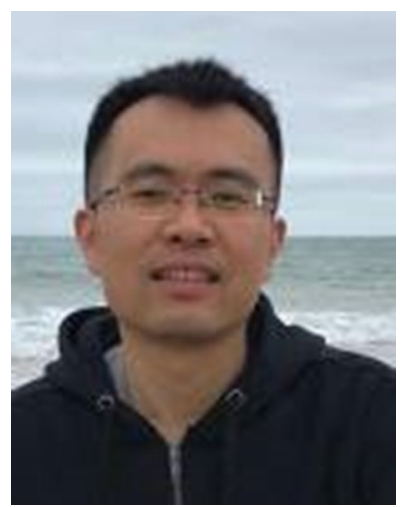

Yi-Jun Xu is a full professor working at State Key Laboratory of Photocatalysis on Energy and Environment, College of Chemistry, Fuzhou University, P. R. China. He is a Fellow of Royal Society of Chemistry (FRSC) and his current research interests primarily focus on the assembly and applications of composite materials in the field of heterogeneous photocatalysis. 